NBER WORKING PAPER SERIES

\title{
OPTIMAL UNEMPLOYMENT INSURANCE \\ WHEN INCOME EFFECTS ARE LARGE
}

\author{
Raj Chetty \\ Working Paper 10500 \\ http://www.nber.org/papers/w10500 \\ NATIONAL BUREAU OF ECONOMIC RESEARCH \\ 1050 Massachusetts Avenue \\ Cambridge, MA 02138 \\ May 2004
}

I thank Julie Cullen, David Card, David Cutler, Amy Finkelstein, Emmanuel Saez, Jesse Shapiro, seminar participants at Harvard, Yale, Stanford, Chicago, Princeton, Berkeley, Northwestern, Madison, and Columbia, and especially Gary Chamberlain, Martin Feldstein, Jerry Hausman, Caroline Hoxby, and Larry Katz for helpful comments. Philippe Bouzaglou and David Lee provided excellent research assistance. Financial support from the National Science Foundation, Harvard University, NBER, and State Farm is gratefully acknowledged. The views expressed herein are those of the author(s) and not necessarily those of the National Bureau of Economic Research.

(C2004 by Raj Chetty. All rights reserved. Short sections of text, not to exceed two paragraphs, may be quoted without explicit permission provided that full credit, including (C) notice, is given to the source. 
Optimal Unemployment Insurance When Income Effects are Large

Raj Chetty

NBER Working Paper No. 10500

May 2004

JEL No. C41, D8, E24, H5, J6

\section{ABSTRACT}

Studies of the consumption-smoothing benefits of unemployment insurance (UI) have found that the optimal benefit level is very small, perhaps even 0 , for conventional levels of risk aversion. In this paper, I derive a formula for the optimal benefit rate in terms of income and price elasticities of unemployment durations, directly inferring risk aversion for the unemployed from their behavioral responses to UI benefits. The optimal rate of social insurance is shown to depend positively on the size of the income elasticity and negatively on the size of the substitution elasticity. I estimate these elasticities using semi-parametric hazard models and variation in UI laws across states and over time. The estimates indicate that income effects account for $70 \%$ of the effect of UI on unemployment durations, and yield an optimal replacement rate around $50 \%$ of preunemployment wages. These results challenge the prevailing view that social safety nets provide minimal welfare gains at a large efficiency cost.

Raj Chetty

Department of Economics

UC- Berkeley

521 Evans Hall \#388

Berkeley, CA 94720

and NBER

chetty@econ.berkeley.edu 


\section{Introduction}

The United States spent approximately $\$ 200$ billion on income security programs in $2000 .^{1}$ The large size and continued growth of social safety nets in the US and other countries raise an important question in public finance. ${ }^{2}$ Estimates of the consumption smoothing benefits of UI by Gruber (1997), Browning and Crossley (2001), and others imply that the optimal benefit level is lower than $10 \%$ of an individual's pre-unemployment wage, and perhaps even 0 , for "reasonable" levels of risk aversion. ${ }^{3}$ The reason is that empirical estimates of the distortionary costs of UI appear to outweigh its consumption-smoothing benefits, which appear to be significantly mitigated by other mechanisms of smoothing income shocks such as spousal labor supply, savings, and borrowing. ${ }^{4}$ The difference between predictions of the optimal benefit level and actual benefit levels, which are on average $50 \%$ of pre-unemployment wages in the US and even higher in European countries, is striking. Do existing studies underestimate the benefits of UI and other large income security programs, or are these programs indeed unjustified on economic grounds?

In this paper, I show that studies which conclude that the optimal UI benefit rate is low implicitly assume that the income effects from UI are small relative to substitution (price) effects, and find that this assumption is rejected by the data. To see the how this assumption is made, consider the standard Baily (1978) model of optimal UI, which is what Gruber uses to calculate the optimal benefit rate. In this model, the optimal benefit level

\footnotetext{
${ }^{1}$ This figure includes the three largest income security programs: In 2000, Unemployment Insurance costs amounted to $\$ 25$ billion (Ways and Means Green Book 2000); Workers Compensation, $\$ 56$ billion (National Academy of Social Insurance); and Survivors Benefits and Disability Insurance, $\$ 113$ billion (Office of Management and Budget).

${ }^{2}$ Krueger and Meyer (2002) document the growth in social insurance around the world.

${ }^{3}$ These results assume a coefficient of relative risk aversion less than 2. Higher levels of risk aversion sharply increase the optimal replacement rate, as shown below.

${ }^{4}$ These findings may seem to be at odds with some recent papers on the optimal path of UI benefits that give high optimal replacement rates (e.g. Davidson and Woodbury (1997), Hopenhayn and Niccolini (1998)). However, these papers consider models where consumption equals income from UI while unemployed, effectively assuming a very large consumption-smoothing role for UI. If this assumption is relaxed, as in Werning (2002), the optimal level of benefits remains very low unless risk aversion is high.
} 
depends on three parameters: (1) the elasticity of unemployment durations with respect to benefits, which quantifies the size of the moral hazard problem; (2) the drop in consumption as a function of UI benefits, which quantifies the consumption-smoothing benefits; and (3) the coefficient of relative risk aversion $(\gamma)$, which reflects the value of having a smoother consumption path. The first two parameters have been estimated using data on the behavior of unemployed individuals (see e.g. Meyer (1990), Gruber (1997)). However, the curvature of the utility function has not been estimated for the population of unemployed individuals. Many economists contend that $\gamma<2$ based on introspection about preferences over gambles, in which case the optimal benefit rate is indeed quite low. But the optimal benefit rate is highly sensitive to the value of $\gamma$, and estimates of risk aversion vary significantly depending on the nature of the risk. ${ }^{5}$ Hence, estimating $\gamma$ for the unemployed is of interest in evaluating the optimal level of UI.

I address this issue by developing a method of estimating $\gamma$ for the unemployed directly from data on their search behavior. I show that in Baily's model of unemployment, there is a connection between the coefficient of relative risk aversion and the ratio of the income and price elasticities of unemployment durations. ${ }^{6}$ That is, large income effects are evidence of a highly curved underlying utility over consumption. Intuitively, if an individual increases effort significantly to recoup lost income when unemployed, that lost income must have raised the marginal utility of consumption significantly, implying that $\gamma$ is large. Since the lost income is so highly valued, it follows that the welfare gain from UI is large and the optimal benefit rate should be relatively high. Hence, the optimal rate of social insurance depends positively on the size of the income elasticity and negatively on the size of the substitution

\footnotetext{
${ }^{5}$ For example, Gertner (1993) and Metrick (1995) overcome this limitation by using actual behavior on game shows and find $\gamma=4$ and $\gamma=0$, respectively. Szpiro (1986) finds $\gamma=2$ using aggregate time series on insured property and insurance premiums. Barsky et. al. (1997) use responses to hypothetical gambles over lifetime income on the Health and Retirment Survey to estimate $\gamma=12$.

${ }^{6}$ This result is an application of the method developed in Chetty (2003), who shows that data on labor supply choices can be used to make inferences about risk aversion without any assumptions beyond those of expected utility theory.
} 
elasticity.

The empirical portion of this paper implements this method by estimating income and price effects for job searchers using variation in UI laws. While there is no formal evidence on the relative importance of income and substitution effects in UI, the conventional view is that substitution effects must dominate income effects because UI benefits are a trivial fraction of lifetime income. In their recent review of the literature on social insurance, Krueger and Meyer (2002) conclude that behavioral responses to benefits are probably large because "UI and WC [workers compensation] lead to short-run variation in wages with mostly a substitution effect." However, this intuition does not account for the fact that most agents enter unemployment with very low assets and are highly credit constrained: Gruber's finding that small variations in UI benefits induce changes in average food consumption directly implies that the representative UI recipient is unable to smooth consumption using permanent income. Such credit constraints make it plausible that income effects play a large role in determining unemployment durations.

I decompose the UI benefit elasticity into an income and price effect using variation in the path of benefits across states in the US and by exploiting the finite duration of UI benefits. For instance, variations in the waiting period for UI benefits permits identification of an income effect. After the first week of unemployment has passed, claimants in states without waiting weeks have effectively received a temporary lump-sum grant relative to claimants in states with waiting weeks. By comparing unemployment exit rates in the two groups of states, we can identify the effect of unearned income on search behavior. Another method of estimating an income elasticity is by examining the effect of UI on unemployment exit hazards after benefits have been exhausted, since benefit levels can only affect unemployment exit rates through an income effect after this point. More generally, it is shown that the time-varying relationship between UI benefit rates and unemployment exit hazards permits inferences about the size of income effects.

Estimates of semi-parametric hazard models for unemployment exit reveal that UI ben- 
efits affect search behavior primarily through income effects. For instance, small lump-sum grants at the beginning of a spell have significant effects on unemployment exit rates in early weeks. In addition, the provision of generous UI benefits continues to lower unemployment exit hazards well past the benefit exhaustion date. Under conservative assumptions on exogenously specified parameters, the results imply that more than $70 \%$ of the effect of UI on unemployment durations comes through an income effect. The large income effect implies that $\gamma \approx 4.75$ for the unemployed and results in an optimal UI replacement rate of approximately 50\%. The estimates suggest that the UI system in the US provides consumption-smoothing benefits that are worth about $1 \%$ of wages, an order of magnitude larger than the welfare gain implied by prior studies. These results challenge the prevailing view that social safety nets provide minimal gains in welfare at a large efficiency cost. ${ }^{7}$

The remainder of the paper is organized as follows. The next section develops a Bailytype model of unemployment and derives a formula for risk aversion and the optimal UI benefit level in terms of income and price elasticities for unemployment durations. Section 3 describes the UI law variation used to estimate these elasticities, summarizes the data, and reports estimates of hazard models. Section 4 translates the hazard estimates into values for risk aversion of the unemployed and computes the optimal UI benefit level. The paper concludes with a discussion of the reason that income effects may be so large for the shortterm unemployed, in contrast with long-term labor supply behavior, where a large literature has found small income effects.

\footnotetext{
${ }^{7}$ Of course, it does not follow that direct government provision of these safety nets is optimal; other methods of insurance provision may improve welfare further.
} 


\section{Income Effects and Unemployment Insurance}

\section{$2.1 \quad$ Model}

This section derives a formula for the optimal UI benefit rate using a representative-agent two-period model of unemployment. ${ }^{8}$ The two-period simplification is made without loss of generality, since the formula for the optimal UI benefit level derived below applies to infinite-horizon or OLG models where agents face repeated unemployment shocks. Also, while the shock analyzed here is unemployment, the methods below can be easily adapted to analyze other programs that insure income shocks such as workers compensation and disability insurance.

The basic structure of the model is as follows. Individuals make consumption and savings decisions in the first period, recognizing that they may be laid off with some exogenous probability at the end of the first period. Agents always supply one unit of labor when employed. In the second period, if they are laid off, individuals choose their unemployment duration deterministically, subject to the level of UI benefits being provided and other resources such as income from spousal labor supply or borrowing. ${ }^{9}$

This model is identical to that of Baily (1978), except that agents choose labor supply directly here instead of choosing it stochastically by picking a level of search intensity and a reservation wage. This simplification of the search problem facilitates the exposition without any loss of generality.

The following notation is used: $s$ denotes saving in period $1, \delta$ is the agent's discount factor, $p$ is the probability of becoming unemployed in period $2, l \in[0,1]$ is labor supply

\footnotetext{
${ }^{8}$ Browning and Crossley (2001) observe that there is substantial heterogeneity among unemployed agents in responses to UI benefits, and argue that conclusions based on the representative-agent Baily model could be misleading. I discuss consequences of relaxing the representative-agent assumption at the end of section 4 .

${ }^{9}$ Note that even though this model has two periods, it remains a static model of unemployment since agents do not make dynamic search decisions. The purpose of the first period is only to allow for distortions in saving as a result of changes in UI benefits.
} 
within the unemployed state in period 2, $w$ is the wage, and $y$ other non-UI income in the unemployed state. In practice, $y$ can include severance payments, spousal earnings, financial assistance from relatives, and borrowing against future income. There is a convex cost of obtaining other income while unemployed, $\eta(y)$, which is intended to flexibly capture the disutility of a spouse working, the cost of taking financial assistance from others, or the cost of borrowing.

Following the existing literature on optimal UI, I assume that utility is additive over consumption and leisure, i.e. there is no complementarity between consumption and leisure (unemployment). ${ }^{10}$ Utility over consumption is given by a concave smooth function $u(c)$. The single consumption good $c$, which is equivalent to total expenditure here, is a composite of all the consumption goods in the economy. The disutility of supplying $l$ units of labor in the unemployed state is given by a convex smooth function $\psi(l)$. In the context of job search, $\psi(l)$ captures both the costs of finding employment for a fraction $l$ of the period and the direct disutility of supplying $l$ units of labor in period 2 .

Unemployment insurance is modeled as a pay-as-you-go system where taxes collected in a given period are used to finance benefits in that period. UI is financed by a $\operatorname{tax} \tau$ on the wages of employed agents in period $2 .{ }^{11} \quad$ To distinguish income and price effects, consider a two-part UI system that pays a lump-sum of $b_{0}$ upon unemployment and a proportional benefit $b$ that is a linear function of the unemployment duration. Hence, total UI benefits for an unemployment duration $(1-l)$ are $b_{0}+b(1-l)$. With this notation, if the individual

\footnotetext{
${ }^{10}$ While this assumption is made primarily to facilitate comparisons with previous studies, it is worth noting that there is some evidence for it. Gruber (1997) finds that agents who anticipate temporary layoffs do not reduce consumption at all while unemployed, suggesting that complementarities between consumption and unemployment are small.

${ }^{11}$ The assumption that the UI tax is collected only in period 2 is made only for modeling convenience. In a more realistic model where the set of workers who are at risk of unemployment is constant over time, imposing the UI tax in all periods would generate identical results to those derived below. If the tax were collected in both periods in the current model, the optimal level of UI would depend on the value of $r-\delta$ because the system would effectively be partially funded.
} 
is unemployed in the second period, he chooses labor supply and unearned income by solving

$$
\max _{l \in[0,1], y} u\left(s+y+b_{0}+(1-l) b+l w(1-\tau)\right)-\psi(l)-\eta(y)
$$

Working backwards to the first period, the individual chooses savings $s$ by solving

$$
\max _{s, l, y} V_{1}=u(w-s)+\delta\left[(1-p) u(s+w(1-\tau))+p\left(u\left(s+y+b_{0}+(1-l) b+l w(1-\tau)\right)-\psi(l)-\eta(y)\right)\right]
$$

The model is closed by a balanced-budget constraint for the provider of UI benefits:

$$
\tau w(1-p+p l)=p\left(b_{0}+b(1-l)\right)
$$

In the empirical implementation below, I use differences in UI laws across states that create variation in $b_{0}$ to estimate income effects. However, to simplify the comparison of my results on optimal UI to the benchmark case analyzed by Baily and Gruber, I compute the optimal UI benefit rate in a system that pays only a proportional benefit $b$. In other words, I derive a formula below that identifies the optimal $b$ when the initial lump-sum payment is restricted to $b_{0}=0 .{ }^{12}$ In this case, the optimal benefit rate $b^{*}$ is given by the value of $b$ that maximizes expected utility given behavioral responses:

$$
\begin{aligned}
b^{*}= & \arg \max _{b} V_{1}(s(b), y(b), l(b)) \\
\text { s.t. } \quad & \tau w(1-p+p l)=p b(1-l)
\end{aligned}
$$

The solution to this optimization problem is simplified by making use of the Envelope conditions $\frac{\partial V}{\partial s}=0, \frac{\partial V}{\partial y}=0, \frac{\partial V}{\partial l}=0$. Letting $u_{c}$ denote the marginal utility of consumption, $c_{1}$

\footnotetext{
${ }^{12}$ I abstract from the optimal lump-sum grant since the goal of this paper is to analyze the optimal level of UI benefits. A recent strand of the literature has focused on richer dynamic search models to analyze the optimal path of UI benefits (Hopenhayn and Niccolini (1997), Werning (2002)). However, the optimal level of benefits continues to depend on essentially the same basic parameters in these models.
} 
consumption in period $1, c_{2}^{e}$ consumption when employed in period 2, and $c_{2}^{u}$ consumption when laid off, the first order condition for the optimal benefit rate is given by

$$
w\left((1-p) u_{c}\left(c_{2}^{e}\right)+p l u_{c}\left(c_{2}^{u}\right)\right) \frac{\partial t}{\partial b}=p(1-l) u_{c}\left(c_{2}^{u}\right)
$$

The intuition for this condition is that the social planner equates the marginal utility of providing another dollar of UI benefits to the agent - the right hand side of the equation - with the cost of raising the UI tax to finance that dollar of benefits - the left hand side. This optimality condition applies to a wide class of dynamic models beyond the simple static framework analyzed here. To see this, note that in any optimization model, envelope conditions will continue to apply, allowing us to focus only on the direct effects of the UI tax and benefits. If the government is required to balance the budget of the UI program within every period, it cannot shift resources intertemporally, and the marginal cost and marginal benefit of changing $b$ coincide exactly with those in the preceding equation.

After some algebraic rearrangement, the optimality condition in (2) can be written as

$$
(1-p)(1-p+p l) \frac{u_{c}\left(c^{u}\right)-u_{c}\left(c^{e}\right)}{(1-p) u_{c}\left(c^{e}\right)+p l u_{c}\left(c^{u}\right)}=\varepsilon_{1-l, b}
$$

To obtain the formula that Gruber uses in his calibration, I follow Baily's method of deriving an approximation to this equation. In my formulation of the model, Baily's simplifications are equivalent to assuming that (1) the probability of unemployment $(p)$ is small and (2) first-order Taylor expansions of $u_{c}(c)$ approximate marginal utility well. Under these assumptions, letting $\gamma=-\frac{u_{c c}}{u_{c}} c$ denote the coefficient of relative risk aversion and 
$\frac{\Delta c}{c}(b)=\frac{c_{2}^{e}-c_{2}^{u}}{c_{2}^{e}}$, the optimal $b^{*}$ is approximately defined by the following implicit equation. ${ }^{13}$

$$
\frac{\Delta c}{c}\left(b^{*}\right) \gamma=\varepsilon_{1-l, b}
$$

This formula shows that the optimal rate of benefits is chosen by trading off the benefits of smoothing consumption across states with the distortionary costs of UI. The distortionary cost is captured on the right hand side of (4) in the elasticity of unemployment durations with respect to the level of benefits. The welfare gain from UI is reflected on the left hand side of (4) in the product of $\frac{\Delta c}{c}(b)$, which quantifies the consumption-smoothing benefits of UI, and $\gamma$, which reflects the value of having a smoother consumption path.

A note on methodology: The formula for the optimal UI benefit rate could be written in terms of the primitives of the model by choosing a parametric specification for $u, \eta$, $\psi$, etc. The advantage of using (4) instead is that the optimal benefit rate can be computed from empirical estimates of behavioral responses such as $\varepsilon_{1-l, b}$ without knowledge of the structure of other insurance mechanisms that the agent can use. In particular, there is no need to explicitly specify the agent's discount factor, the cost of spousal labor supply, or the agent's ability to borrow, each of which may be difficult to estimate.

\subsection{Existing Calibrations}

Several studies have estimated $\frac{\Delta c}{c}(b)$ using data on the behavior of the unemployed. I use Gruber's (1997) estimates of the drop in food consumption during unemployment as a function of the replacement rate $\frac{b}{w}$. More recent work finds fairly similar estimates for the UI system in the US using broader measures of expenditure beyond food consumption and different methods of identification. ${ }^{14}$ In addition, since $c$ is total expenditure in the model,

\footnotetext{
${ }^{13}$ To check the quality of the approximation, I computed the exact solution with CRRA utility $(u(c)=$ $\left.\frac{c^{1-\gamma}}{1-\gamma}\right), l=0$, and $p=.05$. Results differed by at most $3 \%$ for the optimal replacement rate.

${ }^{14}$ Gruber (1998) uses data from the CEX to confirm that similar results are obtained for other expenditures besides food. Browning and Crossley (2001) find more limited consumption-smoothing benefits for UI in
} 
$c$ is likely to be more sensitive to changes in UI than food, insofar as food is a necessity. Hence, Gruber's food estimates should place a lower bound on the consumption-smoothing benefits of UI. The estimates from his baseline specification are

$$
\frac{\Delta c}{c}\left(\frac{b}{w}\right) \approx .24-.28\left(\frac{b}{w}\right)
$$

This equation shows that consumption would drop by $24 \%$ in the absence of UI, and reflects the fact that consumption drops by approximately $10 \%$ at the mean UI replacement rate of $50 \%$. These estimates reveal that individuals have substantial resources to mitigate the impact of unemployment on consumption besides government-provided unemployment insurance. This is the reason that $b^{*}$ is much lower using the Baily-Gruber method than in models where UI is assumed to be the only source of income while unemployed, which find optimal replacement rates from 70-100\% (e.g. Flemming (1978), Davidson and Woodbury (1997), Hopenhayn and Niccolini (1998)). ${ }^{15}$

Substituting (5) into (4) gives a simple expression for the optimal wage replacement rate $\frac{b}{w}^{*}:$

$$
{\frac{b^{*}}{w}}^{*}=.86-3.57 \frac{\varepsilon_{1-l, b}}{\gamma}
$$

Plugging in an estimate of $\varepsilon_{1-l, b}=0.432$ based on Meyer (1990), Gruber obtains the following relationship between $\frac{b}{w}^{*}$ and $\gamma \cdot{ }^{16}$

$$
\frac{b}{w}^{*}=.86-\frac{1.6}{\gamma}
$$

This formula shows that the optimal replacement rate is highly sensitive to the value of $\gamma$,

Canada. Stephens (2001) and Aguiar and Hurst (2004) find results similar to those of Gruber for the food consumption drop during unemployment using different methods and datasets.

${ }^{15}$ In view of the importance of other sources of income in practice, these papers can be interpreted as giving optimal replacement rates for consumption while unemployed, rather than optimal replacement rates for UI benefits.

${ }^{16}$ Gruber's consumption-smoothing estimates are for the entire population, not just those who take up UI. Meyer's original elasticity estimate of 0.8 is only for UI recipients. Given that non-UI recipients do not respond to the level of UI benefits, Gruber multiplies Meyer's elasticity by the takeup rate of UI to arrive at the 0.432 elasticity for his calculations. 
especially at the lower end of the range:

\begin{tabular}{|c|c|c|c|c|c|c|}
\hline$\gamma$ & 1 & 2 & 3 & 4 & 5 & 10 \\
\hline$\frac{b}{w}^{*}$ & 0 & 0.06 & 0.33 & 0.46 & 0.54 & 0.7 \\
\hline
\end{tabular}

Gruber concludes that unless risk aversion is very high $(\gamma>2)$, "the distortions of UI to search behavior are so large that the optimal benefit level is fairly low." Unfortunately, estimates of $\gamma$ are limited and are usually drawn from introspection about choices between gambles or experiments with small stakes that may not be informative about the risk preferences of unemployed agents. ${ }^{17}$ The danger of using estimates based on introspection is underscored by the recent experimental work of Holt and Laury (2002), who show that subjects exhibit much higher degrees of risk aversion when playing with large real stakes than when introspecting about hypothetical gambles. Moreover, recent work on consumption of durables and liquidity constraints suggests that change in marginal utility induced by a temporary income shock may be very different from the effect of permanent shocks. Browning and Crossley (2003) show that the consumption of small durables such as clothes can reduce risk aversion with respect to temporary income shocks, because agents can reduce expenditures by postponing purchase of these durables without much of a welfare cost. On the other hand, Chetty (2004) and Chetty and Szeidl (2004) show that the consumption of large durables that involve transaction costs such as housing and vehicles amplify risk aversion with respect to temporary or moderate shocks, because they force agents to concentrate all their changes on a small share of their budget. These results point to the advantages of estimating $\gamma$ directly from data on the behavior of unemployed agents.

\footnotetext{
${ }^{17}$ One exception is Hausman (1985), who estimates risk aversion for disability insurance applicants directly from data on application and award rates. Estimates from his method are somewhat sensitive to functional form assumptions, ranging from $\gamma=1$ to $\gamma=4$ depending on the discount rate.
} 


\subsection{Estimating $\gamma$ from Income and Price Elasticities}

To derive an estimator for $\gamma$, let us begin from the first order condition that determines the agent's choice of $l$ when unemployed:

$$
(\widetilde{w}-b) u_{c}\left(c_{\text {unemp }}\right)=\psi_{l}
$$

where $c_{\text {unemp }}=s+y+b_{0}+(1-l) b+l \widetilde{w}$ is consumption in the unemployed state and $\widetilde{w}=w(1-\tau)$ denotes the net-of-tax wage that the individual earns by working. I begin under the assumption that exogenous increases in UI benefits and unearned income do not induce changes in the level of savings and other income - in other words, I assume $\frac{\partial s}{\partial b}=$ $0, \frac{\partial s}{\partial b_{0}}=0, \frac{\partial y}{\partial b}=0, \frac{\partial y}{\partial b_{0}}=0$. Taking account of these crowdout effects only raises the estimates of $\gamma$ and the optimal benefit level further, as discussed below. ${ }^{18}$

Implicit differentiation of (8) with respect to $b_{0}$ and $b$ yields

$$
\begin{aligned}
\frac{\partial l}{\partial b_{0}} & =-\frac{(\widetilde{w}-b) u_{c c}}{(\widetilde{w}-b)^{2} u_{c c}-\psi_{l l}} \\
\frac{\partial l}{\partial b} & =\frac{u_{c}-(1-l)(\widetilde{w}-b) u_{c c}}{(\widetilde{w}-b)^{2} u_{c c}-\psi_{l l}}
\end{aligned}
$$

Using a Slutsky decomposition, the pure price (substitution) effect $\frac{\partial l^{c}}{\partial b}$ on labor supply is given by

$$
\frac{\partial l^{c}}{\partial b}=\frac{\partial l}{\partial b}-(1-l) \frac{\partial l}{\partial b_{0}}
$$

\footnotetext{
${ }^{18}$ The expression for $\gamma$ derived below also ignores changes in the UI tax rate $t$ associated with changes in $b$, by assuming $\frac{\partial \widetilde{w}}{\partial b}=0$. This simplification is unlikely to affect the empirical estimates of $\gamma$ for two reasons: (1) The change in the UI tax needed to finance an increase in UI benefits is small if $p$, the fraction of unemployed agents, is small; in the limit, as $p \rightarrow 0, \frac{\partial t}{\partial b} \rightarrow 0$. In practice, the wage base is very large relative to total UI benefits, so $p$ is indeed quite small. (2) In practice, UI is financed by a payroll tax on the first $\$ 10,000$ of each worker's salary. For the majority of workers, the UI tax therefore has only an income effect. Changes in total income due to changes in the UI tax are small based on the first reason. Hence, the direct effects of changes in $b$ are likely to dwarf the effects of changes in $t$.
} 
This implies

$$
\begin{aligned}
\frac{\partial l / \partial b_{0}}{\partial l / \partial b-(1-l) \partial l / \partial b_{0}} & =\frac{\partial l / \partial b_{0}}{\partial l^{c} / \partial b}=-(\widetilde{w}-b) \frac{u_{c c}}{u_{c}} \\
\Rightarrow \gamma=-\frac{u_{c c}}{u_{c}} c_{u n e m p} & =\frac{\partial l / \partial b_{0}}{\partial l^{c} / \partial b} \frac{c_{u n e m p}}{\widetilde{w}-b}
\end{aligned}
$$

This expression for $\gamma$ can be written in terms of more familiar income and compensated benefit (price) elasticities. Define the UI income and compensated benefit elasticities as follows.

$$
\begin{aligned}
\varepsilon_{1-l, b_{0}} & =\frac{\partial(1-l)}{\partial b_{0}} \frac{b_{0}}{1-l} \\
\varepsilon_{1-l, b}^{c} & =\frac{\partial\left(1-l^{c}\right)}{\partial b} \frac{b}{1-l}
\end{aligned}
$$

The benefit elasticity can be interpreted as the percentage change in unemployment durations resulting from a $1 \%$ increase in the proportional benefit rate. Similarly, the income elasticity is the percentage change in durations resulting from a $1 \%$ increase in unearned income from $U I^{19}$ With this notation, it follows that

$$
\gamma=\frac{\varepsilon_{1-l, b_{0}}}{\varepsilon_{1-l, b}^{c}} \frac{c_{u n e m p}}{\widetilde{w}-b} \frac{b}{b_{0}}
$$

Equation (12) gives an intuitive estimator for risk aversion $(\gamma)$ in terms of observable price and income effects on unemployment durations when utility is additive over $c$ and $l$. The key concept is that $\gamma$ is directly related to the ratio of the income and price effects. That is, large income effects are evidence of a highly curved underlying utility. The intuition is as follows. The income elasticity is large if a small reduction in income leads to a large increase in labor supply. A rational agent chooses labor supply by equating the marginal

\footnotetext{
${ }^{19}$ Note that neither of these elasticities depends on other unearned income, $y$, or the level of savings, $s$, simplifying the empirical estimation by reducing data requirements.
} 
utility of a dollar of consumption with the marginal disutility of earning that dollar, as in (8). If the marginal disutility of labor is constant, the agent increases his labor supply sharply in response to a reduction in unearned income if the marginal utility of consumption rises sharply when his income falls; in other words, if utility over consumption is highly curved. Put differently, if an individual increases effort significantly to recoup lost income when unemployed, that lost income must have great value to him, implying that he is highly risk averse. In the more general case where the marginal disutility of labor is not constant, the income elasticity must be normalized by the compensated benefit elasticity as in (12) to net out this effect and isolate $\gamma$.

It may be surprising that a unique value for $\gamma$ can be identified in this deterministic setting, because the labor supply data we observe provide only ordinal information about utility. To see this more clearly, suppose we transform utility when unemployed into $v(c, l, y)=f(u(c)-\psi(l)-\eta(y))$ by a non-linear function $f$. This transformation leaves observed unemployment durations $(l)$ unchanged, but changes the curvature of $u(c)$. Does this imply that risk aversion is unidentified, i.e. there are infinitely many values of $\gamma$ that could be associated with an observed set of unemployment durations? To see why it does not, recall that (12) was derived under the assumption that utility is additive over consumption and leisure. Any non-linear $f$ would destroy the identifying additivity assumption, resulting in $v_{c l} \neq 0$. This logic generalizes beyond the additive case. Once the value of $v_{c l}$ has been pinned down, data on labor supply (or unemployment durations) are sufficient to make inferences about risk preferences because no non-linear transformation will leave $v_{c l}$ unaffected.

A natural concern is that the estimate of $\gamma$ from this method may be highly sensitive to the cross-partial $v_{c l}$, which may difficult to estimate for the composite commodity $c$. Estimates of demand functions have shown that complementarity between consumption and labor is generally non-zero but varies in sign across goods (Browning and Meghir, 1991). Fortunately, in the case of unemployment, the value of $v_{c l}$ can be sufficiently bounded that inferences 
about $\gamma$ under the additivity assumption prove to be quite accurate. The intuition for this bounding argument, which is formalized in Appendix $\mathrm{A}$, is that $v_{c l}$ can be inferred from the consumption drop during unemployment in a world with perfect insurance markets, $\frac{\Delta c^{*}}{c}$. With perfect insurance, if agents choose to reduce consumption while unemployed, it must be because consumption complements labor $\left(v_{c l}>0\right)$; if they choose to raise consumption, $v_{c l}<0$. The estimator of $\gamma$ in (12) overestimates the true $\gamma$ if $v_{c l}<0$ because part of the increase in marginal utility when the agent works (and earns) less is misattributed to risk aversion instead of complementarity between consumption and leisure.

A calibration exercise shows that the estimate of $\gamma$ is biased upward by $16 \%$ if $\frac{\Delta c^{*}}{c}=$ $-10 \%$, i.e. if expenditure would ideally be increased by $10 \%$ while unemployed. The lower bound $\frac{\Delta c^{*}}{c}=-10 \%$ is likely to accomodate any potential deviation from additivity for three reasons. First, Gruber finds that the consumption of workers who anticipate a layoff does not change at all during unemployment, suggesting that deviations from additivity are small. Second, if workers did not cut back on other sources of income while unemployed when UI benefits were raised, they could finance an expenditure increase of $24 \%$ over their consumption while employed. The fact that they choose not to do so suggests that $v_{c l} \nless 0$ for the composite commodity $c$. Third, evidence on the expenditure drop during retirement suggests that, if anything, $v_{c l}>0$ because of the opportunity for home production (Aguiar and Hurst, 2004). Finally, even if the true $\frac{\Delta c^{*}}{c}=-10 \%$ despite this evidence, the resulting $16 \%$ reduction in $\gamma$ from the benchmark estimate below $(\gamma=5)$ does not affect the main conclusions on optimal UI significantly. I therefore focus on the additive case below.

The estimator in (12) was derived under the assumption that savings and other sources of income while unemployed are not crowded out by UI benefits. When crowdout occurs, the expression in (12) gives a lower bound for $\gamma$. A proof of this result is given in Appendix B. Intuitively, in the presence of crowdout, the income effect is underestimated because a $\$ 1$ increase in $b_{0}$ causes total unearned income to rise by less than a $\$ 1$ while unemployed, because the agent also comes into unemployment with lower $s$ and $y$. Conversely, the pure 
price effect is overestimated because a compensated increase in benefits lowers labor supply and total income while unemployed, which raises the optimal $s$ and $y$, inducing a further reduction in $l$. Since the estimator of risk aversion is based on the ratio of the income and price effects, the expression in (12) underestimates $\gamma$ when $s$ and $y$ are endogenous to the level of UI benefits.

It should be noted that the estimate of $\gamma$ informs us about the curvature of utility over the composite good $c$, which is ultimately the risk aversion parameter relevant for evaluating optimal UI, as shown in (4). To see this more precisely, suppose there are $N$ consumption goods, $c_{1}, \ldots, c_{N}$, with prices $p_{1}, \ldots, p_{N}$. If utility over these goods is $g\left(c_{1}, \ldots, c_{N}\right)$, the agent's decision problem while unemployed can be written as a two-stage budgeting problem:

$$
\begin{aligned}
& \max _{l \in[0,1], y} u\left(s+y+b_{0}+(1-l) b+l w(1-\tau)\right)-\psi(l)-\eta(y) \\
& \text { s.t. } u(c)=\left\{\max g\left(c_{1}, \ldots, c_{N}\right) \mid \sum p_{i} c_{i}=c\right\}
\end{aligned}
$$

Writing the agent's problem in this way shows that $\gamma$ is the curvature of the indirect utility function $u(c)$ over total expenditure $(c)$. Estimating the curvature of $u$ directly is valuable insofar as this parameter can be very sensitive to the specification of $g$. For instance, Browning and Crossley (2003) show that unemployed agents reduce expenditures by delaying the purchase of a new jackets, socks, and other small durables. They argue that these postponements do not cause much of a reduction in utility. In terms of the notation above, if $c_{1}$ denotes consumption of clothes, the idea is that $c$ can be reduced during unemployment by reducing consumption of $c_{1}$ sharply, preventing $u_{c}$ from rising a lot during unemployment. By estimating the change in $u_{c}$ directly, the formula for optimal UI proposed here accounts for these effects without requiring knowledge of the relative costs of reducing expenditure on clothes or food. More generally, beyond unemployment, the estimator gives a method of computing the relevant risk aversion parameter wherever labor supply behavior can be observed, providing a parsimonious means of evaluating the welfare 
benefits of many redistributive programs.

Once $\gamma$ has been identified, it is easy to compute the optimal UI benefit rate. Plugging the estimator for $\gamma$ into (6) gives an expression for $\frac{b}{w}^{*}$ that is a function of parameters that can be estimated from data on unemployment durations:

$$
\frac{b}{w}^{*}=k_{1}-k_{2} \frac{\varepsilon_{1-l, b} \varepsilon_{1-l, b}^{c}}{\varepsilon_{1-l, b_{0}}}
$$

where $k_{1}$ and $k_{2}$ are constants that can be calculated from the consumption-smoothing estimates of Gruber (1997) and the representative agent's wage, unearned income, and labor supply. This formula shows that the general wisdom that large behavioral responses justify smaller social insurance programs is incorrect. Indeed, the optimal level of insurance may be higher when the uncompensated elasticity is larger. In analogy with results on the deadweight cost of taxation, the optimal level of insurance depends inversely only on the magnitude of the compensated benefit elasticity $\left(\varepsilon_{1-l, b}^{c}\right)$, not the uncompensated UI benefit elasticity. Only if higher social insurance benefits cause distortions through a price effect can one infer that agents are "gaming" the system, generating deadweight loss. These results indicate the importance of decomposing estimates of benefit elasticities into price and income effects to calculate the optimal size of any social insurance program. The next section describes how variation in laws across states and time in the US can be exploited to conduct such a decomposition in the case of unemployment insurance.

\section{Empirical Analysis}

\subsection{Identification Strategy}

Unemployment Insurance is a federally mandated program run by individual states. After an involuntary job separation, workers are eligible for benefits from the state government if they have a sufficiently high amount of earned income during the past year. The program 
is large: In 1998, approximately seven million individuals in the United States received unemployment benefits and the program's outlays exceeded $\$ 20$ billion dollars.

In all states and at all points in time, the path of benefits for any claimant who is totally unemployed can be characterized by four basic parameters. First, the weekly benefit amount is a function of the claimant's past wage history and number of dependents. Second, there is a maximum potential duration for benefits, which also depends on the claimant's past wage history. Third, many states have a waiting week that must be served before benefits are received. Finally, among the states with waiting weeks, some have a "retroactive date" within the first month after which the benefit for the waiting week is given. Figure 1 illustrates the variation in laws by graphing potential benefit paths for three claimants earning $\$ 400$ per week in different states.

The rich variation in the path of benefits across states and over time allows us to study how labor supply responds to variations in unearned income and the net-of-UI wage. ${ }^{20}$ Variation in weekly benefit amounts permits identification of the uncompensated elasticity of unemployment durations with respect to the benefit level. I use two different sources of identification to decompose this uncompensated elasticity into an income effect and a price effect. The first is the variation in waiting weeks across states and time. After the first week of unemployment has passed, claimants in states without waiting weeks have effectively received a temporary lump-sum grant relative to claimants in states with waiting weeks. The grant is temporary because all claimants are entitled to the same total level of benefits; it is just that the first week of benefits is instead received in the 27th week of the spell in states with waiting weeks. Since agents with rational expectations will not anticipate reaching the 27 th week with high probability at the time of unemployment, they are temporarily richer if they do not face a waiting week. As the lump-sum grant variations induced by waiting

\footnotetext{
${ }^{20}$ Cross-state and time variation in UI laws has previously been used to estimate the effects of unemployment benefit generosity on unemployment exit rates (Meyer, 1990), spousal labor supply (Cullen and Gruber, 2000), precautionary saving (Engen and Gruber, 1995), and consumption smoothing (Gruber, 1997).
} 
weeks are small ( $\$ 200$ on average), checking whether they are associated with temporary changes in search behavior provides a strong test of the hypothesis that UI benefits have large income effects.

The logic underlying the second source of identification is more subtle, and takes advantage of the fact that UI benefits have a finite duration in conjunction with the difference in UI benefits across states and time. To see how this works, compare the search behavior at several points during the unemployment spell of two identical claimants, one in Massachusetts and one in California, each earning $\$ 400 /$ week prior to unemployment. In MA, the claimant receives approximately $\$ 250$ per week for up to 26 weeks; in CA, he receives $\$ 150$ per week. Focus first on individuals who have already exhausted their UI benefits. Massachusetts residents who have exhausted their benefits have accumulated $\$ 2600$ more in benefits than their counterparts in California. Since there are no subsequent differences in UI payments, the higher UI benefits paid to those in MA can only affect search behavior after week 26 via an income effect, assuming that there are no other systematic differences between those who remain unemployed after 26 weeks in the two states. ${ }^{21}$ Now consider the week prior to benefit exhaustion. Here higher UI benefits not only raise unearned income but also decrease the net-of-UI wage by $\$ 100$ in the next week. As a result, in week 25 , MA residents have less incentive to search not only because they have more unearned income, but also because they have a lower wage. Finally, consider the first week of an unemployment spell. At this point, MA residents have a lower effective wage for the next 26 weeks but have not yet accumulated more unearned income than those in CA. Higher UI benefits affect behavior primarily through the price channel at the beginning of the spell.

These examples imply that one can make inferences about income and price effects by comparing the effect of UI benefits on unemployment exit hazards over time. If an increase in UI benefits reduces the hazard rate of unemployment exit much more early in a spell than

\footnotetext{
${ }^{21}$ The potential for selection bias from correlations between the composition of claimants who remain unemployed for a long time and the level of UI benefits is addressed below.
} 
later in a spell, the price effect must be of greater importance than the income effect. If higher UI benefits continue to reduce hazard rates late in an unemployment spell, income effects must be important, and price effects less so. This qualitative intuition is used to pin down estimates of income and price elasticities formally in Section 4.

It may be surprising that the small changes in transitory income induced by the law variations described above can have detectable income effects because the resulting change in lifetime income is trivial. The reason that temporary income fluctuations have an effect is that the unemployed have very low levels of liquid assets and are highly credit constrained. This is evident in Gruber's (1997) finding that increases in UI benefits reduce the fall in consumption from employment to unemployment and reduce the rise in consumption from unemployment to re-employment, implying that small changes in income during unemployment do have a non-trivial effect on resources.

\subsection{Data}

The data used in this study are from the 1985-1987 and 1990-1996 panels of the Survey of Income and Program Participation (SIPP). The SIPP collects information from a sample of approximately 30,000 households every four months for a period of two to three years. The interviews I use span the period from the beginning of 1985 to the middle of 2000 . At each interview, households are asked questions about their activities during the past four months, including weekly labor force status. Unemployed individuals are asked whether they received unemployment benefits in each month. ${ }^{22}$ Other data about the demographic and economic characteristics of each household member are also collected.

I make five exclusions on the original sample of job leavers to arrive at my core sample. First, following previous studies of UI, I restrict attention to prime-age males (over 18 and

\footnotetext{
${ }^{22}$ The ability to identify UI takeup is one advantage of using the SIPP rather than the Current Population Survey. Another advantage is that the SIPP is a panel dataset, making it more suitable to measure unemployment durations. The CPS only gives a cross-section of ongoing spells.
} 
under 65). Second, I include only the set of individuals who report searching for a job at some point after losing their job, in order to eliminate from the analysis individuals who have dropped out of the labor force. Third, I exclude individuals who report that they were on temporary layoff at any point during their spells, since they might not have been actively searching for a job. ${ }^{23}$ Fourth, I exclude individuals who have less than three months work history within the survey because there is insufficient information to estimate preunemployment wages for this group. Finally, I focus on individuals who take up UI within one month after losing their job because the method of estimating $\gamma$ developed above uses information from the behavior of unemployed agents who receive UI benefits. ${ }^{24}$ The potential sample selection bias related to UI takeup that arises from this exclusion is addressed below.

These exclusions leave 4,457 individuals in the core sample. Table 1 gives summary statistics for this group, which looks reasonably representative of the general population. The median UI recipient is a high school graduate and has pre-UI gross annual earnings of $\$ 20,726$ in 1990 dollars. As noted above, most claimants have limited financial assets before their unemployment spells begin: median liquid wealth net of unsecured debt is only $\$ 186$.

The key covariates for the analysis are the main aspects of each state's unemployment insurance law in each year. The raw data on UI laws were obtained from the Employment and Training Administration (various years), and supplemented with information directly from individual states. ${ }^{25}$ The computation of weekly benefit amounts deserves special mention. Measurement error and inadequate information about pre-unemployment wages for many

\footnotetext{
${ }^{23}$ Katz and Meyer (1990) show that whether an individual considers himself to be on temporary layoff is endogenous to the duration of the spell; recall may be expected early in a spell but not after some time has elapsed since a layoff. Excluding temporary layoffs can therefore potentially bias the estimates. To check that this is not the case, I include temporary layoffs in some specifications of the model.

${ }^{24}$ Since I focus only on UI recipients, the estimates of risk aversion apply only to this subgroup of the unemployed. However, given that the relevant $\gamma$ for UI is the one that applies to those who are actually affected by the system, this qualification does not affect our calculation of the optimal level of UI if the predicted optimum is close to the mean level of UI benefits that we observe, which is in fact the case.

${ }^{25}$ I am grateful to Julie Cullen and Jon Gruber for sharing their simulation programs, and to Suzanne Simonetta and Loryn Lancaster in the Department of Labor for providing detailed information about state UI laws from 1984-2000.
} 
claimants make it difficult to simulate the potential UI benefit level for each agent precisely. I use three independent approaches to proxy for each claimant's (unobserved) actual UI benefits, all of which yield similar results. First, I use published state average benefits in lieu of each individual's actual UI benefit amount. Second, I proxy for the actual benefit using published maximum weekly benefit amounts, which are the primary source of variation in benefit levels across states. ${ }^{26}$ The third method involves simulation of each individual's weekly UI benefit using a two-stage procedure. In the first stage, I predict the claimant's pre-unemployment annual income using information on education, age, tenure, occupation, industry, and other demographics. The prediction equation for pre-UI annual earnings is estimated on the full sample of individuals who report a job loss at some point during the sample period. ${ }^{27}$ In the second stage, I use the predicted wage as a proxy for the true wage, and assign the claimant unemployment benefits using the simulation program.

The mean weekly benefit amount based on the simulation method is $\$ 166$ and the mean replacement rate for pre-UI earnings is approximately $50 \%{ }^{28}$ There is considerable crossstate and time variation in unemployment benefits, from an average weekly benefit amount of $\$ 102$ in Louisiana to $\$ 217$ in Massachusetts in 1990 . $15 \%$ of the UI claimants began receiving benefits immediately upon unemployment (i.e. did not have a waiting week), while another $16 \%$ were eligible to receive a retroactive payment for the waiting week after their spell extended past a certain length (typically 4 weeks). Thus, $31 \%$ of the individuals in the sample receive a lump sum grant equivalent to one week of benefits early in the spell relative to claimants who face a UI system that has a waiting week and makes no retroactive

\footnotetext{
${ }^{26}$ Most states replace $50 \%$ of a claimant's wages up to a maximum benefit level.

${ }^{27}$ Since many individuals in the sample do not have a full year's earning's history before a job separation, I define the annual income of these individuals by assuming that they earned the average wage they report before they began participating in the SIPP. For example, individuals with one quarter of wage history are assumed to have an annual income of four times that quarter's income.

${ }^{28} \mathrm{UI}$ benefits are taxed; however, most individuals elect to pay taxes on UI benefits at the end of the year rather than have taxes withheld. Insofar as income during the unemployment spell is the primary determinant of behavior for liquidity-constrained households (and not income obtained when taxes are filed), the pre-tax benefit amount is relevant for the present analysis.
} 
payments. Finally, the maximum potential duration is either 26 or 39 weeks for many claimants. This is because the federal government enacted an emergency program to extend unemployment benefits by thirteen weeks between November 1990 and February 1994 during a national recession.

The computation of unemployment durations using the survey responses are described in Appendix C. It is helpful to have a sense of the mean unemployment exit hazards in the sample before analyzing the effect of covariates on these hazards. ${ }^{29}$ The solid line in Figure 2 shows the empirical hazards for the core sample. Though the hazard rate fluctuates throughout, there are sharp spikes at $t=17$ and $t=35$. These spikes reflect a reporting artefact known as the "seam effect," which is common in longitudinal panels such as the SIPP. To see how the seam effect arises, recall that the SIPP data is collected by interviewing individuals every four months about their activities during the past four months, which is termed the "reference period." Individuals tend to repeat answers about weekly job status. As a result, they under-report transitions in labor force status within reference periods and overreport transitions on the "seam" between reference periods. Hence, many spells of unemployment appear to last for exactly the length of one or two reference periods, which correspond to lengths of 17 and 35 weeks. The dashed hazard function plotted in Figure 2 shows the empirical hazards for spells that did not begin on a seam, and as one would expect, the two spikes no longer exist. ${ }^{30}$ The potential for bias from the seam effect is addressed below.

\footnotetext{
${ }^{29}$ The hazard rate at week $t$ is the probability that a spell ends in week $t$ conditional on it lasting for at least $t$ periods. That is, $h_{t}=\operatorname{Pr}(d u r=t \mid d u r>=t)$.

${ }^{30}$ The remaining fluctuations in the hazard rate are generally consistent with the findings of Meyer (1990), who uses an administrative dataset of UI recipients. One exception is that we do not see a spike in the hazard rate around the time of benefit exhaustion (26 weeks), as documented e.g. in Katz and Meyer (1990). The main reason for this difference is the exclusion of temporary layoffs, which drive most of the spike in the data used by Katz and Meyer.
} 


\subsection{Hazard Model Estimates}

The key empirical results of this paper can be illustrated with two sets of graphs. I first divide states into two categories: those that have a waiting week and no retroactive payment and those that have either no waiting week or make a retroactive payment for the waiting week early in the spell. ${ }^{31}$ Claimants in the latter set of states $(\mathrm{INC}=1)$ get an extra week of benefits up front relative to claimants in the former group $(\mathrm{INC}=0){ }^{32}$ Note, however, that if two individuals have the same maximum potential duration of benefits, the total weeks of benefits that both claimants can get remains the same; it is just that the individual in the $\mathrm{INC}=1$ state has one week of benefits shifted from the end to the beginning. One should therefore expect this shift of income to have a short-lived effect of the probability of survival. Figure 3 shows that this is indeed the case by plotting Kaplan-Meier survival curves for the groups. Individuals in the INC $=1$ states have lower job-finding hazards in the first month after unemployment, but begin to catch up to the other states in subsequent weeks. Note that the survival functions are plotted conditional on having a spell that lasts for more than one week, since no one with a one week unemployment spell can receive UI in states with waiting weeks.

I then divide states into two different categories: those that have average weekly benefit amounts above the mean and those below the mean. Figure 4 plots Kaplan-Meier survival curves for these two groups. Individuals who receive more benefits have a lower job-finding hazard rate throughout the spell, since the two survival curves continue to diverge even after week 20. Figure 5 makes this point clearer by plotting empirical hazards for the same two groups. Higher UI benefits are clearly associated with lower unemployment exit hazards

\footnotetext{
${ }^{31}$ More precisely, the two groups contain unique state/year pairs (e.g. Michigan/1990 or Alabama/1995), since laws within a state can change over time. I simplify terminology by referring to comparisons across "states" in the text, but the actual comparison is always across state/year pairs.

${ }^{32}$ The states that make a retroactive payment for the waiting week are initially placed in the $I N C=1$ category because claimants in these states usually get an extra week of benefits if they remain unemployed for more than a month, which most do. Specifications 6 and 7 below consider the retroactive date and waiting week variation separately.
} 
late in an unemployment spell, well past the typical benefit exhaustion point of 26 weeks. These figures suggest that UI has a large income effect on search behavior based on the identification strategy described above.

I formalize the results shown in these graphs by estimating Cox survival models. ${ }^{33}$ An attractive feature of the Cox model is that it is semiparametric in that it does not impose any functional form on the baseline unemployment exit rates in each week. Consequently, the benefit and income effects are identified solely from the cross-state and time variation in UI laws. The Cox specification assumes a proportional-hazards form for the hazard rate $t$ weeks after unemployment:

$$
h_{t}=\alpha_{t} e^{\beta X_{t}}
$$

where $X_{t}$ denotes a set of covariates that can vary over time. Table 2 presents estimates of several specifications of this model. The coefficients reported are hazard ratios $\left(e^{\beta^{j}}\right)$, which can be interpreted as the ratio of the hazard when covariate $j$ equals $X^{j}+1$ to the hazard when the covariate is $X^{j}$. All specifications only include unemployment spells that last for more than week for the reasons described above.

I begin by discussing the results in the simplest specification, then show the results of a series of robustness checks, and finally address potential concerns about selection bias in the estimates. In specification (1), as in most others, I use the average UI benefit level in a given state and year in place of each claimant's actual UI benefit for reasons discussed above. The only controls included in this specification are the unemployment rate and a dummy for being on the seam between interviews; dropping these variables from the specification has no

\footnotetext{
${ }^{33}$ Abrevaya and Hausman (1999) and Romeo (2001) show that standard hazard models could yield biased estimates when unemployment durations are mismeasured due to the seam effect. For simplicity, I follow the standard approach because the estimates from the SIPP data appear to be consistent with those found in other studies that did not have mismeasured durations. I also attempt to mitigate the mismeasurement problem by including a dummy for being "on the seam" and find that this has little effect on the estimates of the key UI benefit coefficients because the baseline hazards in the Cox model pick up the effect. In addition, in the structural estimation procedure described below, I address the mismeasurement problem explicitly by maximizing a likelihood function for mismeasured durations subject to the recall errors. Correcting for these reporting errors has no appreciable effect on the results.
} 
appreciable effect on the results. The estimates from this specification, which are typical, indicate that a $10 \%$ increase in the weekly benefit amount reduces the hazard rate by $4.2 \%$ in the first week of an unemployment spell, matching the results of previous studies. ${ }^{34}$ This effect is statistically significant at the $1 \%$ level. The coefficient on the interaction between weeks unemployed and the weekly benefit amount is precisely estimated and close to zero. The point estimate implies that a $10 \%$ increase in the weekly benefit amount would reduce the hazard rate by $3.8 \%$ twenty weeks into an unemployment spell. The coefficient on the interaction between the benefit exhaustion dummy and benefit rate is also insignificant but fairly precisely estimated. ${ }^{35}$ These results suggest that higher UI benefits reduce search effort primarily via an income effect rather than a price effect. If the reduction in the net-of-UI wage were the primary source of changes in search behavior, higher benefits would reduce search effort much more at the beginning of a spell than in later weeks. Moreover, the effect of higher benefits on job finding after benefits were exhausted would be much lower if price effects dominated.

The next group of estimates reported in the table capture the time-varying effect of the INC variable defined above. The estimates indicate that the provision of an additional week of benefits at the beginning of a spell has large effects on short-run search behavior. An extra week of unearned income through UI benefits reduces the hazard rate by approximately $14 \%$ in the first two months after unemployment. However, as shown in Figure 3, the hazard rates of the INC $=1$ group are $20 \%$ higher than those of the INC $=0$ group in the third month. After the fourth month, there in no discernible difference in the behavior of claimants in the $\mathrm{INC}=0$ and INC $=1$ states. The difference between the INC coefficients in months 1 and 3 is statistically significant at the $5 \%$ level. The temporary nature of income effect is to be

\footnotetext{
${ }^{34}$ See e.g. Krueger and Meyer (2002), who review the results of several studies on UI benefits and unemployment durations.

${ }^{35}$ These results are consistent with Katz and Meyer (1990b), who use administrative data on unemployment durations. They interact the UI benefit rate with a dummy for being three weeks away from exhaustion and find no significant effects.
} 
expected, since both groups ultimately are entitled to the same total benefits. It is just that the INC $=1$ group temporarily has more cash because they receive an extra week of benefits near the beginning of their spells.

Specification (2) adds a full set of controls, including industry and occupation dummies, year and month dummies, a 10 piece log-linear spline for the claimant's pre-unemployment wage, and other demographic variables. The addition of these controls leaves the coefficients of the key UI law variables virtually unchanged. In specification (3), I use simulated UI benefits for each individual (using the two-stage method described above) instead of state averages. ${ }^{36}$ The hazard ratio on UI benefits rises insignificantly and other coefficients remain unchanged. Note that in this specification, the UI benefit coefficients continue to be identified from variation in UI laws, and not the cross-sectional variation in benefit levels within a state that results from heterogeneity in wages. This is because pre-unemployment wages are controlled for flexibly using the spline.

In specification (4), I include state fixed effects, identifying the model from changes in state laws. The coefficients on UI benefit levels are essentially unchanged and remain precisely estimated. The point estimates on the INC variables are also very similar to those in specification (1). However, since only three states changed their waiting periods or retroactive provisions between 1985 and 2000, the standard errors on the INC coefficients are higher in this specification.

Finally, specification (5) confirms that the income and price effects do not emerge for the "control group" of individuals who do not get UI. ${ }^{37}$ The point estimates are close to zero

\footnotetext{
${ }^{36}$ When weekly benefit amounts generated from actual reported wages are used, the point estimate of the benefity elasticity falls to 0.03 and the standard error rises significantly. To test the hypothesis that this problem arises from classical measurement error of the regressor, I restricted attention to the set of individuals who had low variability of pre-unemployment quarterly wages (and for whom we can estimate actual UI benefits most precisely). For this subset, the estimates match those reported in specification (3) and are statistically significant.

${ }^{37}$ Results are similar for the set of job losers who are ineligible for UI, who arguably are a better "control" because takeup of UI is endogenous. However, the UI-ineligible group consists of part-time workers who have very low levels of earned income before unemployment and may therefore not be similar to the average
} 
and the null hypothesis that the income and benefits elasticities are the same as those for the UI claimants can be rejected. These results support the claim that the UI laws are causal, i.e. the results are not spuriously driven by unobservable heterogeneity in the labor market across states or time that is correlated with both UI laws and unemployment durations.

Table 3 reports the results of additional robustness checks. In specification (6), I omit states that have waiting periods and later make a retroactive payment, identifying the INC coefficient exclusively from variations in whether a state has a waiting period or not. Conversely, in (7), I omit states that do not have a waiting period, thereby identifying the INC coefficient exclusively from variations in whether a state makes a retroactive payment or not. The estimates of the INC coefficients are very similar in both cases, supporting the claim that it is the extra week of benefits and not an omitted variable that is driving the estimates.

In specification (8), I include temporary layoffs in the analysis, to check that the endogeneity of temporary layoff status with respect to spell duration is not biasing the results. In (9), I include the entire set of UI recipients, not just those who claimed UI in the month they became unemployed. While the estimate of the UI benefit effects remain the same, the pattern in the INC coefficients is somewhat weaker. This is not surprising, since the one week waiting period has no impact on the benefit path of claimants who wait for more than a week to claim UI benefits anyway. In fact, it should be viewed as further evidence that the earlier specifications are identifying causal effects of the extra week of income on the behavior of claimants who take up UI immediately. Finally, in specification (10), I use the maximum benefit levels in a state/year pair to proxy for actual UI benefits and focus on individuals with weekly wages above $\$ 400$, whose benefits are most likely to be determined by the maximum benefit. The estimates of the key coefficients remain the same as in earlier specifications.

UI claimant. Note that the sample size for the non-UI unemployed is large because we have no means of excluding discouraged workers (see Appendix C) and UI receipt is underreported in the SIPP (see the audit study of Marquis and Moore, 1990). 
Additional specification and robustness checks did not suggest any problems. Analysis of the Schoenfeld residuals showed that the proportional hazards assumption was not violated for any regressor except the seam dummy, which is to be expected given that the recall problem need not be related to the unemployment exit rate. In addition, allowing for Gamma-distributed unobserved individual heterogeneity using Meyer's (1990) modification of the Prentice-Gloeckler model further strengthened the evidence in favor of large income effects.

In summary, there is robust evidence that the substitution effect of UI benefits on unemployment durations is small, and that the income effect is large. This results is consistent with other studies that have found large labor supply responses to transitory income fluctuations. For example, Mincer (1962) found that married women's labor supply responds 2-3 times as much to transitory fluctuations in husbands' incomes as it does to permanent differences in husbands' incomes. More recently, Cullen and Gruber (2000) exploit variation in UI laws to estimate an income elasticity for wives labor supply between -0.49 and -1.07 .

\subsection{Sample Selection Concerns}

Before proceeding to use these results to estimate risk aversion, I address some potential concerns about the estimation strategy. First, one might worry that the endogeneity of the UI takeup decision is biasing the estimates of the income effect using the INC variation. However, there is no evidence of selection based on the waiting period or retroactive payment; regressing a dummy for UI receipt on INC shows no relationship between the two variables. Moreover, even if there were a selection effect due to variations in the waiting period, one would expect it to bias the estimated income elasticity downward. If there is a fixed cost to UI takeup, a waiting week should deter individuals who anticipate short unemployment spells, making the average unemployment spell longer in the $\mathrm{INC}=0$ states.

A second concern is that the endogeneity of takeup with respect to the level of benefits 
biases the estimate of the UI benefit elasticity. In my sample, a $10 \%$ increase in the benefit rate is associated with a $1 \%$ increase in the probability of UI takeup in the first month of unemployment. ${ }^{38}$ If the marginal individuals who decide to take up UI when benefits rise tend to have shorter unemployment spells on average, the estimate of the uncompensated benefit elasticity will be biased toward zero. The magnitude of the bias can be gauged by assuming that the individuals who are added to the sample through this selection effect are drawn randomly from the group who do not takeup UI. The empirical hazards for the non-UI group are on average 1.1 times as large as those of the UI recipients. In practice, the marginal individual who takes up UI is likely to anticipate a longer UI spell than the average agent who does not take up UI, so the 1.1 ratio provides an upper bound for the size of the selection bias. Starting from an initial takeup rate of 50\%, a $10 \%$ increase in benefits will cause the average hazard rate to rise through this selection effect by approximately $\frac{1 \%}{50 \%} *(1.1-1)=0.2 \%$. It follows that a $10 \%$ increase in UI benefits may cause at most a $4.4 \%$ reduction in the true hazard rate, in comparison to the estimate of $4.2 \%$ that was obtained when selection issues were ignored. Hence, this selection effect is negligible.

Finally, the estimate of the income elasticity that exploits the time-varying effect of UI benefits on the hazard rate could also be affected by selection bias. The set of individuals who remain unemployed for a long time and/or exhaust UI benefits may be systematically different in high UI and low UI regimes. If tastes are uncorrelated with search technology, only those agents who have intrinsically low job-finding hazards will remain unemployed for an extended period of time in low-benefit states; more able types will exit unemployment quickly if UI pays little. Consequently, late in an unemployment spell, the selection effect should reduce the average hazard in low UI benefit states relative to high benefit states, working against finding the negative relationship between UI and the hazard rate that was

\footnotetext{
${ }^{38}$ The probability of taking up UI at any point during the spell rises by $2 \%$ for a $10 \%$ increase in UI benefits. This is exactly equal to the estimate reported by Anderson and Meyer (1997), who use a much larger dataset on benefit takeup.
} 
documented. Of course, preferences and search technologies could in principle be correlated in a way such that agents with high job-finding hazards are more likely to remain unemployed in high UI regimes. However, the data suggest that this is unlikely to be the case for two reasons. First, the fact that controlling for unobserved heterogeneity using the MeyerPrentice-Gloeckler method strengthens the results suggests that selection is, if anything, working against finding an association between UI benefits and search behavior late in the spell. Second, the interaction of observable measures of heterogeneity such as education and occupation dummies with the level of UI benefits does not affect the estimates. Since controlling for observed heterogeneity does not affect the results, the estimates are unlikely to be very sensitive to unobservable heterogeneity either.

\section{Implications for Risk Aversion and Optimal UI}

This section translates the hazard model estimates into the income and uncompensated benefit elasticities relevant for the static model of unemployment developed in section 2 . These elasticity estimates are then used to impute $\gamma$ using (12).

I begin by rewriting the formula for $\gamma$ in terms of the uncompensated benefit elasticity using the Slutsky equation:

$$
\gamma=\frac{\varepsilon_{1-l, b_{0}}}{\varepsilon_{1-l, b}^{c}} \frac{c_{u n e m p}}{\widetilde{w}-b} \frac{b}{b_{0}}=\frac{\frac{b}{b_{0}} \varepsilon_{1-l, b_{0}}}{\varepsilon_{1-l, b}-\frac{b}{b_{0}} \varepsilon_{1-l, b_{0}}} \frac{c_{u n e m p}}{\widetilde{w}-b}
$$

To calibrate (15), note that the average replacement rate in the sample is approximately $50 \%$, so $b \simeq \frac{1}{2} \widetilde{w}$ and $\widetilde{w} \simeq c_{e m p}$, implying

$$
\gamma \simeq 2 \frac{\frac{b}{b_{0}} \varepsilon_{1-l, b_{0}}}{\varepsilon_{1-l, b}-\frac{b}{b_{0}} \varepsilon_{1-l, b_{0}}} \frac{c_{u n e m p}}{c_{e m p}}
$$

Gruber (1997) estimates $\frac{c_{u n e m p}}{c_{e m p}} \simeq 0.9$ at the average replacement rate, yielding the following 
formula for $\gamma$ :

$$
\gamma \simeq 1.8 \frac{\frac{b}{b_{0}} \varepsilon_{1-l, b_{0}}}{\varepsilon_{1-l, b}-\frac{b}{b_{0}} \varepsilon_{1-l, b_{0}}}
$$

I calculate the income and price elasticities using the estimates of specification (2) in Table 2, the benchmark case with controls. The coefficient on the UI benefit rate implies that a $10 \%$ (uncompensated) increase in the UI benefit rate is associated with a $3.6 \%$ increase in unemployment durations, i.e. $\varepsilon_{1-l, b}=0.36{ }^{39}$

To calculate the income elasticity, recall that $\varepsilon_{1-l, b_{0}}$ is the percent change in duration that results from a $1 \%$ increase in UI income through a lump-sum grant. There are two sources of identification for this elasticity, as noted above. The first is to look at the effect of UI benefits on search behavior after the benefit exhaustion week $(T)$, at which point changes in UI benefits correspond to changes in lump-sum grants that have only income effects. In other words, a $1 \%$ increase in $b$ at $t=T+1$ is equivalent to a $1 \%$ increase in $b_{0}$ at this point. Hence, when $t=T+1$,

$$
\frac{b}{b_{0}} \varepsilon_{1-l, b_{0}}=\frac{b}{b_{0}} \frac{\partial(1-l)}{\partial b_{0}} \frac{b_{0}}{1-l}=\varepsilon_{1-l, b}^{t=T+1}
$$

Using the time-varying coefficients on the benefit elasticity, the hazard model estimates imply that a $10 \%$ increase in $b$ causes a $2.6 \%$ increase in duration based on the change in hazard rates after benefits are exhausted, i.e. $\frac{b}{b_{0}} \varepsilon_{1-l, b_{0}}=\varepsilon_{1-l, b}^{t=T+1}=0.26$.

The second method of estimating the income elasticity is to use the lump-sum grant variation resulting from differences in waiting weeks and retroactive dates. The estimates of the $I N C$ coefficients from specification (2) imply that a 1 week grant of benefits reduces the hazard rate in the first month by $12 \%$. Translating this estimate into an income elasticity requires specification of $\frac{b}{b_{0}}$, the ratio of total income the agent receives from the proportional UI benefit in the second period to the income he gets from the one-week lump sum grant. In

\footnotetext{
${ }^{39}$ All duration elasticities are calculated using the hazard ratios and the baseline hazards recovered from the estimation of specification (2).
} 
the deterministic two-period model of unemployment, the length of the second period should be interpreted as the agent's "smoothing horizon," over which he is credit constrained and must balance his budget. ${ }^{40}$ A longer smoothing horizon will result in a larger income elasticity, since the 1 week grant corresponds a smaller percentage increase in unearned income. A reasonable lower bound for this horizon is one month, insofar as agents who are paid on a monthly basis must find ways to smooth over this period. Denoting the total benefits earned from the proportional UI benefit over the first one month (four week) horizon by $b_{1-4}$, it follows that

$$
\frac{b}{b_{0}} \varepsilon_{1-l, b_{0}}=\frac{b_{1-4}}{b_{0}} \frac{\partial(1-l)}{\partial b_{0}} \frac{b_{0}}{1-l} \approx \frac{\Delta(1-l)}{1-l} / \frac{\Delta b_{0}}{b_{1-4}}
$$

The hazard model estimates imply $\frac{\Delta(1-l)}{1-l}=0.12$. Using the estimates of the mean empirical hazards, the average agent expects to receive about 2.8 weeks of UI benefits within the first month (given that most states have a waiting week). Hence, the 1 week income grant is equivalent to a $36 \%$ increase UI income over the month, i.e. $\frac{\Delta b_{0}}{b_{1-4}}=.36$. It follows that $\frac{b}{b_{0}} \varepsilon_{1-l, b_{0}}=0.27$.

Reassuringly, the two estimates of the income elasticity are similar despite being computed from independent sources of variation. Approximately $70 \%(.26 / .36)$ of the effect of UI benefits on unemployment durations comes through an income effect, leaving only $30 \%$ for the pure price effect. Plugging the estimates into (16) implies $\gamma \approx 4.75$. Unemployed agents appear to be highly risk averse: Reductions in income caused by unemployment raise the marginal utility of income sharply.

\footnotetext{
${ }^{40}$ The first method of estimating the income elasticity is consistent with any smoothing horizon, since $b_{0}=b$ there. Put differently, the percentage change in the benefit level is unaffected by the period over which those benefits are accrued.
} 


\subsection{Summary of Structural Estimation}

The advantage of the simple calculations of risk aversion above is transparency: it is clear how the income and price elasticities are identified from variation in the UI laws. However, while I have tried to err on the side of underestimating $\gamma$, the preceding calculations require a number of approximations. Most importantly, the static formulation of unemployment ignores the uncertainty and dynamics inherent in the job search process, assuming instead that agents are able to choose their durations deterministically. The static model also abstracts from other dynamics, such as the potential change in consumption and asset holdings over the unemployment spell. A natural concern is whether the estimates of risk aversion from the static analysis are robust to the incorporation of dynamics and uncertainty.

To address this concern, I also estimated $\gamma$ using numerical maximum-likelihood methods in a standard dynamic job search model, as in Wolpin (1987). ${ }^{41}$ In the interest of space, the basic setup and results of this model are summarized here, and details are given in Chetty (2004). I consider a discrete-time setting in which each period corresponds to one week. Agents become unemployed exogenously with some level of assets. Once unemployed, agents have an infinite horizon, but anyone who remains after unemployed after one year goes on welfare permanently after that point. Re-employment is an absorbing state. Agents choose a level of consumption and search effort in every period. The baseline probability of finding a job is specified flexibly as in the Cox model, and higher search effort in a given week raises the probability of finding a job in that week linearly. I use a CRRA specification for utility over consumption, and a power specification for the disutility of search effort. Each agent solves a dynamic programming problem to choose a consumption and search effort path that maximizes expected utility in each period, subject to the UI law he faces and the parameter

\footnotetext{
${ }^{41}$ The model I estimate differs from Wolpin's model in two ways: (1) It permits utility over consumption to be non-linear (i.e. does not assume risk neutrality); (2) Since non-linear utility makes analytic solutions infeasible, agents choose only search effort (and not reservation wages) to make the estimation computationally tractable.
} 
vector that governs preferences and search technology.

Exogenous parameters are chosen to match empirical estimates if available. In the benchmark specification, I set the annual discount rate at $10 \%$ per year and the welfare payment after one year of unemployment at $25 \%$ of the agent's wage. The agent is assumed to become unemployed with $\$ 500$ of savings and faces a borrowing constraint of $\$ 5000$. These parameters are chosen to generate a consumption drop that matches or overstates Gruber's estimate of a $10 \%$ consumption drop during unemployment at the mean UI benefit level. It is shown that overstating the consumption drop leads to underestimating the key parameter of interest, $\gamma$. Sensitivity checks reveal that the estimates are fairly robust to perturbations in these exogenous parameters.

The model is estimated in three steps: (1) Dynamic programming problems are solved numerically given a parameter vector and UI law to obtain unemployment exit probabilities for a representative agent in each state/year pair; (2) A likelihood function is generated using these probabilities by pooling the data from all the states; and (3) Iterating over the first two steps, the likelihood is maximized to estimate the cost of search effort, baseline job finding probabilities, disutility of labor, and $\gamma$.

The maximum likelihood estimates for all the parameters are reasonable. The estimate of $\gamma$ concurs with the reduced-form results: in the benchmark case, $\gamma=6.2$ with a standard error of 1.5. In addition, the structural estimate of $\gamma$ appears to be identified from precisely the variation in UI laws that one would expect based on the reduced-form results. To evaluate the source of identification for $\gamma$, I maximized a partial likelihood function where $\gamma$ was held fixed at 2.5 and all other parameters were chosen by maximizing likelihood. The predicted hazards from this "constrained ML" procedure match the levels and path of the mean empirical hazards in the sample as do the estimates from the original unconstrained maximization. However, when $\gamma$ is constrained to be low, the model fails to explain the persistent divergence in hazard rates between high-UI and low-UI regimes late in the unemployment spell shown in Figure 4. In other words, a high level of risk aversion is required to 
explain the fact that UI benefits continue to reduce search effort late in an unemployment spell. As I have stressed in describing the identification strategy, the fact that UI benefits continue to affect unemployment exit hazard rates late in a spell is equivalent to the statement that income effects are large relative to price effects. Hence, both the reduced-form and structural estimates of $\gamma$ are identified by the size of income effects relative to price effects from UI. These findings corroborate the claim that the approximate formula for $\gamma$ derived from the static model provides a reasonably good estimate of risk aversion.

\subsection{The Costs and Benefits of UI}

Based on the Baily-Gruber formula for $\frac{b}{w}^{*}$ given in (6), the estimate of $\gamma=4.75$ implies an optimal replacement rate for UI greater than $50 \%$. This calculation takes into account the existence of private market and informal insurance mechanisms that could be crowded out by the provision of UI, suggesting that there is a role for social insurance to improve welfare in this case. ${ }^{42}$

It is helpful to estimate the magnitude of the welfare gain that can be obtained from the provision of UI. Using an approach similar to that in Lucas (1987), the benefits of UI can be quantified by computing the certainty equivalent for the policy change - how much would consumption have to be increased in order to give an agent the same welfare gain as the provision of UI? An exact answer to this question requires knowledge of the agent's objective function and constraints while unemployed, such as the disutility of search effort, the costs of spousal labor supply, etc. A much less ambitious goal is quantifying the pure consumption-smoothing benefits of UI, ignoring the behavioral responses it induces. To do this, suppose agents have CRRA utility $\left(u(c)=\frac{c^{1-\gamma}}{1-\gamma}\right)$. Returning to our two-period unemployment model, based on Gruber's estimate that consumption would fall by $24 \%$ in

\footnotetext{
${ }^{42}$ The importance of taking these effects into account has been emphasized in recent work by Golosov and Tsyvinski (2003), whose simulations show that the benefits of social insurance can in principle be almost entirely eliminated by the crowdout of privately-provided insurance mechanisms.
} 
the absence of UI, the expected utility of consumption in the second period without UI is

$$
E u^{0}=(1-p) \frac{(w)^{1-\gamma}}{1-\gamma}+p \frac{(0.76 w)^{1-\gamma}}{1-\gamma}
$$

Using Gruber's consumption smoothing estimates, a UI replacement rate of $50 \%$ will raise consumption while unemployed by 14 percentage points. Suppose this increase is financed by an equivalent reduction in consumption while employed, so that total output is unchanged (in other words, ignore moral hazard costs). Then the expected utility of consumption with this UI system in period 2 is

$$
E u^{1}=(1-p) \frac{\left(w\left(1-0.14 \frac{p}{1-p}\right)\right)^{1-\gamma}}{1-\gamma}+p \frac{(0.9 w)^{1-\gamma}}{1-\gamma}
$$

The benefit of UI provision can be computed by estimating the percentage increase in the wage, $\alpha$, that would raise expected utility without UI to the level of expected utility with $\mathrm{UI}$ in period $2{ }^{43}$ Formally, $\alpha$ is defined by the following implicit condition

$$
(1-p) \frac{(w(1+\alpha))^{1-\gamma}}{1-\gamma}+p \frac{(0.76 w(1+\alpha))^{1-\gamma}}{1-\gamma}=E u^{1}
$$

The following table lists the percentage wage increase that matches the welfare gain from consumption smoothing via UI for various level of risk aversion. The probability of unemployment is taken as $p=5 \%$.

\begin{tabular}{|c|c|c|c|c|c|c|}
\hline$\gamma$ & 1 & 2 & 3 & 4 & 5 & 10 \\
\hline$\alpha$ & 0.0014 & 0.0031 & 0.0052 & 0.0076 & 0.0104 & 0.0306 \\
\hline
\end{tabular}

The income and substitution effects estimated in this study imply that the existing unemployment insurance system in the US, which replaces roughly $50 \%$ of pre-unemployment

\footnotetext{
${ }^{43}$ It is sufficient to look only at expected utility in the second period of the model because we are ignoring all behavioral changes, including savings. Hence, utility in the first period is unchanged by UI.
} 
wages, generates consumption smoothing benefits that are worth roughly $1 \%$ of labor income. Since UI constitutes about $20 \%$ of income security payments in the US, if income and price effects are similar for other income shocks, income security programs in the US could add approximately $5 \%$ of value to GDP via consumption-smoothing benefits (ignoring moral hazard costs). This estimate is an order of magnitude larger than that implied by studies that use lower values of risk aversion, effectively assuming that the compensated elasticity of durations with respect to UI benefits is large.

Several caveats regarding the details of the calculations of optimal UI deserve mention. First, I have excluded temporary layoffs from the analysis, and am ignoring distortions that UI may cause in the level of unemployment by assuming that the system is perfectly experience rated for employers. ${ }^{44}$ Second, this analysis ignores general-equilibrium effects caused by higher UI benefits. These effects can raise the optimal benefit rate further since UI has the added benefit of improving the efficiency of production in equilibrium. ${ }^{45}$ Third, I have confined my analysis to a representative-agent setting with a simple UI system that is universal and pays a constant level of benefits. Browning and Crossley's (2001) finding that the consumption-smoothing benefits of UI tend to be concentrated amongst lowasset individuals suggests that relaxing these assumptions may yield different conclusions on optimal UI. In particular, the representative-agent model will understate the value of UI relative to a model that aggregates agents' welfare using a utilitarian criterion, because the average difference in marginal utilities while employed and unemployed is larger when shocks are concentrated on a subset of the population. In such a setting, an asset-tested UI system may offer opportunities for further welfare gains. Fourth, the conclusions of this study are relevant for the US; the optimal level of UI in other economies may be different, depending on the structure of the informal social safety net. For example, Browning and Crossley

\footnotetext{
${ }^{44}$ Feldstein (1978) and Topel (1983) present evidence showing a strong relationship between the rate of temporary layoffs, UI benefits, and lack of experience rating.

${ }^{45}$ Acemoglu and Shimer (1999) show that UI can be efficiency improving in equilibrium.
} 
find a smaller consumption-smoothing role for UI in Canada, and the curvature of utility may be lower there as well. Finally, it should be emphasized that the result of this paper is a statement about the optimal level of benefits and not the optimal method of provision of those benefits. For instance, individual UI private savings accounts, as proposed by Feldstein and Altman (1998), may be a more efficient method of provision than government transfers.

\section{Conclusion}

An array of empirical studies have found that social insurance programs such as unemployment insurance, workers compensation, and disability insurance induce large behavioral responses such as reduced labor force participation. Based on these results, some have concluded that social insurance programs cause large efficiency losses and that the optimal size of the safety net is small. ${ }^{46}$ The results of the present paper caution against drawing these conclusions from estimates of large uncompensated benefit elasticities. Optimal social insurance policies depend on the magnitude of income effects relative to substitution effects. Hence, just as computing the deadweight loss and revenues from a tax requires that we distinguish the compensated (Hicksian) elasticity from the uncompensated (Marshallian) elasticity, computing the benefits and efficiency costs of social insurance programs requires knowledge of both elasticities as well.

The practical importance of distinguishing the uncompensated benefit elasticity from the compensated elasticity is evident in the case of unemployment insurance. Using crossstate and time variation in unemployment insurance laws, we found that the compensated benefit elasticity is small relative to the uncompensated elasticity. The estimates imply that unemployed agents are highly risk averse, and that the optimal wage replacement rate is around $50 \%$ for unemployment insurance in the US.

\footnotetext{
${ }^{46}$ See Krueger and Meyer (2003) for a review of this literature.
} 
The large income effect for unemployed agents is consistent with evidence of large "added worker effects" (Mincer, 1962) but may be surprising to those familiar with the static labor supply literature, where most studies find small or nonexistent income effects. ${ }^{47}$ Unlike most labor supply elasticities, the estimates in this paper are identified from transitory fluctuations in income for a set of agents who are highly credit-constrained. One reason that income effects might be especially large for transitory shocks is that a large part of household budgets are pre-committed to items that are unadjustable in the short run. Mortgage or rental payments, car loan payments, and expenses for some types of services are costly to adjust, and therefore likely to be retained during short unemployment spells. ${ }^{48}$ These commitments force individuals to bear the full impact of a shock on a small set of consumption goods such as food and clothing. Consequently, small reductions in unearned income can quickly raise the marginal utility of income, causing agents to increase their labor supply sharply in response. ${ }^{49}$

Interestingly, these types of commitments seem to be the motivation for unemployment insurance at a positive level. In the Arizona State Benefit Adequacy Study, Burgess et. al. (1981) define a measure of benefit adequacy that is "reflected by the total of necessary/obligated expenses for the entire household." Normatively, whether these commitments are the reason for large income effects or not, the empirical results of this paper contradict the prevailing view that unemployment insurance provides minimal gains in welfare at a large efficiency cost.

\footnotetext{
${ }^{47}$ See e.g. Blundell and MaCurdy (1999), who survey a set of recent labor supply studies.

${ }^{48}$ Gruber (1998) finds that less than $5 \%$ of the unemployed move out of their homes during a spell. Estimates of $(S, s)$ policiess for cars by Eberly (1995) and Attanasio (2000) also suggests that a large fraction of the unemployed are likely to retain previously purchased vehicles during a spell.

${ }^{49}$ Chetty (2004) develops and tests a model of consumption commitments and preferences over wealth.
} 


\section{References}

Abrevaya, Jason and Jerry Hausman, "Semiparametric Estimation with Mismeasured Dependent Variables: An Application to Duration Model for Unemployment Spells," Massachusetts Institute of Technology Mimeo (1999).

Acemoglu, Daron and Robert Shimer, "Efficient Unemployment Insurance," Journal of Political Economy 107 (1999), 893-928.

Aguiar, Mark and Erik Hurst, "Consumption vs. Expenditure," NBER Working Paper 10307 (2004).

Anderson, Patricia and Bruce Meyer, "Unemployment Insurance Takeup Rates and the After-Tax Value of Benefits," Quarterly Journal of Economics 112 (1997), 913-937.

Atkinson, Anthony. and John Micklewright, "Unemployment Compensation and Labor Transitions: A Critical Review," Journal of Economic Literature 29 (1991), 1679-1727.

Attanasio, Orazio, "Consumer Durables and Inertial Behavior: Estimation and Aggregation of Ss Rules for Automobiles," Review of Economic Studies 67 (2000), 667-696.

Baily, Martin, "Some Aspects of Optimal Unemployment Insurance," Journal of Public Economics 10 (1978), 379-402.

Barsky, Robert B., F. Thomas Juster, Miles S. Kimball, and Matthew D. Shapiro, "Preference Parameters and Behavioral Heterogeneity: An Experimental Approach in the Health and Retirement Study," Quarterly Journal of Economics, CXII (1997), 537-580.

Browning, Martin and Costas Meghir, "The Effects of Male and Female Labor Supply on Commodity Demands," Econometrica 59 (1991), 925-951.

Browning, Martin and Timothy Crossley, "Unemployment Insurance Levels and Consumption Changes," Journal of Public Economics 80 (2001), 1-23.

Browning, Martin and Timothy Crossley, "Shocks, Stocks, and Socks: Smoothing Consumption over a Temporary Income Loss," Canadian International Labour Network Working Paper 27.

Burgess, Paul, Jerry Kingston, Robert St. Louis, and Joseph Sloan, "Changes in Spending Patterns Following Unemployment," U.S. Department of Labor Employment and Training Administration Occasional Paper 81-3, Washington D.C. (1981).

Chetty, Raj, "A New Method of Estimating Risk Aversion," NBER Working Paper 9988 (2003).

Chetty, Raj, "Consumption Commitments, Unemployment Durations, and Local Risk Aversion" NBER Working Paper 10211 (2004).

Chetty, Raj and Adam Szeidl, "Consumption Commitments and Asset Prices," UCBerkeley mimeo, 2004.

Cullen, Julie and Jonathan Gruber, "Does Unemployment Insurance Crowd Out Spousal Labor Supply?" Journal of Labor Economics 18 (2000), 546-572.

Davidson, Carl and Stephen A. Woodbury, "Optimal Unemployment Insurance," Journal of Public Economics 64 (1997) 359-387. 
Eberly, Janice, "Adjustment of Consumers' Durables Stocks: Evidence from Automobile Purchases," Journal of Political Economy 102 (1994), 403-436.

Employment and Training Administration, Significant Provisions of State Unemployment Insurance Laws, Washington D.C.: U.S. Government Printing Office (various years).

Engen, Eric and Jonathan Gruber, "Unemployment Insurance and Precautionary Savings," Journal of Monetary Economics 47 (2001), 545-579.

Feldstein, Martin, "The Effect of Unemployment Insurance on Temporary Layoffs," American Economic Review 68 (1978), 834-46.

Feldstein, Martin and Daniel Altman, "Unemployment Insurance Savings Accounts," National Bureau of Economic Research Working Paper 6860 (1998).

Flemming, J.S., "Aspects of Optimal Unemployment Insurance," Journal of Public Economics 10 (1978), 403-425.

Gertner, Robert, "Game Shows and Economic Behavior: Risk-Taking on 'Card Sharks'," Quarterly Journal of Economics, 108 (1993), 507-22.

Golosov, Mikhael, and Aleh Tsyvinski, "Optimal Taxation with Endogenous Insurance Markets," UCLA mimeo (2003).

Gruber, Jonathan, "The Consumption Smoothing Benefits of Unemployment Insurance," American Economic Review 87 (1997), 192-205.

Gruber, Jonathan, "Unemployment Insurance, Consumption Smoothing, and Private Insurance: Evidence from the PSID and CEX," Research in Employment Policy 1 (1998), 3-31.

Hausman, Jerry, "The Econometrics of Nonlinear Budget Sets," Econometrica 53 (1985), $1255-1282$.

Holt, Charles and Susan Laury, "Risk Aversion and Incentive Effects in Lottery Choices," American Economic Review 92 (2002), 1644-55.

Hopenhayn, Hugo and Juan Pablo Niccolini, "Optimal Unemployment Insurance," Journal of Political Economy 105 (1997), 412-438.

Katz, Lawrence and Bruce Meyer, The Impact of the Potential Duration of Unemployment Benefits on the Duration of Unemployment," Journal of Public Economics 41 (1990) 45-72.

Krueger, Alan and Bruce Meyer, "Labor Supply Effects of Social Insurance," NBER Working Paper 9014, 2002.

Lucas, Robert E., Jr., Models of Business Cycles, Basil Blackwell: New York, 1987.

Marquis, Kent and Jeffrey C. Moore. "Measurement Errors in SIPP Program Reports," in Proceedings of the 1990 Annual Research Conference, 721-45. Washington D.C.: U.S. Bureau of Census, 1990.

Metrick, Andrew, "A Natural Experiment in Jeopardy!," American Economic Review, 85 (1995), 240-253.

Meyer, Bruce D., "Unemployment Insurance and Unemployment Spells," Econometrica, Volume 58, Issue 4 (1990), 757-782. 
Mincer, Jacob "Labor Force Participation of Married Women," in Aspects of Labor Economics. National Bureau of Economic Research (1962).

Romeo, Charles J.. 2001. "Controlling for Seam Problems in Duration Model Estimates with Application to the Current Population Survey" Journal of Human Resources 36(3), 467-499.

Stephens, Melvin, "The Long-Run Consumption Effects of Earnings Shocks," The Review of Economics and Statistics 83 (2001), 28-36.

Szpiro, George, "Measuring Risk Aversion: An Alternative Approach," The Review of Economics and Statistics, 68 (1986), 156-159.

Topel, Robert, "On Layoffs and Unemployment Insurance," American Economic Review 73 (1983), 541-549.

Werning, Ivan, "Optimal Unemployment Insurance with Unobservable Savings," MIT mimeo (2002).

Wolpin, Kenneth I., "Estimating a Structural Search Model: The Transition from School to Work," Econometrica, Volume 55, Issue 4 (Jul. 1987), 801-817. 


\section{A Estimation of $\gamma$ with complementarity}

Suppose the agent's utility function over consumption, labor, and other income while unemployed is given by a function $v(c, l, y)$ that may be non-additive. The agent's first order condition for $l$ is:

$$
(\widetilde{w}-b) v_{c}\left(c_{\text {unemp }}, l, y\right)=-v_{l}
$$

where $c_{\text {unemp }}=s+y+b_{0}+(1-l) b+l \widetilde{w}$ as before. I continue to assume that exogenous increases in UI benefits do not induce changes in the level of savings and other income, i.e. $\frac{\partial s}{\partial b_{0}}=0, \frac{\partial s}{\partial b}=0$, etc. here. This assumption is relaxed in Appendix B.

Implicit differentiation of (17) with respect to $b_{0}$ and $b$ and algebra as in the main text yields

$$
\begin{aligned}
\frac{\partial l / \partial b_{0}}{\partial l / \partial b-(1-l) \partial l / \partial b_{0}} & =\frac{\partial l / \partial b_{0}}{\partial l^{c} / \partial b}=-(\widetilde{w}-b) \frac{u_{c c}}{u_{c}}-\frac{v_{c l}}{v_{c}}(1-l) \\
\Rightarrow \gamma=-\frac{u_{c c}}{u_{c}} c_{u n e m p} & =\frac{c_{u n e m p}}{\widetilde{w}-b} \frac{\partial l / \partial b_{0}}{\partial l^{c} / \partial b}+\frac{c_{u n e m p}}{\widetilde{w}-b} \frac{v_{c l}}{v_{c}}(1-l)
\end{aligned}
$$

Let $\widehat{\gamma}$ denote the estimator for risk aversion when $v$ is additive $\left(v_{c l}=0\right)$. Then (19) can be rewritten as

$$
\gamma=\widehat{\gamma}+\frac{c_{u n e m p}}{\widetilde{w}-b} \frac{v_{c l}}{v_{c}}(1-l)
$$

I now relate the $\frac{v_{c l}}{v_{c}}$ parameter to the change in consumption when unemployed in a world with perfect insurance and credit markets. Suppose the agent can trade consumption fairly between the two states by purchasing state-contingent commodities prior to the start of period 2 in the model of Section 2. Since labor supply is fixed at 1 in the employed state, he will choose consumption in the two states by maximizing expected utility

$$
\begin{array}{ll} 
& \max _{c^{e}, c^{u}, l}(1-p) v\left(c^{e}, 1\right)+p v\left(c^{u}, l\right) \\
\text { s.t. } & (1-p) c^{e}+p c^{u}=(1-p) w+p w l \equiv \bar{W}
\end{array}
$$

The agent's first-order condition for consumption is obtained by equating marginal utilities across the two states:

$$
v_{c}\left(c^{e}, 1\right)=v_{c}\left(c^{u}, l\right)
$$


Taking a first-order Taylor approximation to this equation around $c^{e}$ and $l=1$ gives

$$
\begin{aligned}
v_{c}\left(c^{e}, 1\right) & =v_{c}\left(c^{e}, 1\right)+v_{c c}\left(c^{u}-c^{e}\right)+v_{c l}(l-1) \\
\Rightarrow v_{c l}(1-l) & =v_{c c}\left(c^{u}-c^{e}\right) \\
\frac{v_{c l}}{v_{c}}(1-l) & =-\frac{v_{c c}}{v_{c}} c^{e} \frac{c^{e}-c^{u}}{c^{e}}=\gamma \frac{\Delta c^{*}}{c}
\end{aligned}
$$

where $\frac{\Delta c^{*}}{c}$ denotes the "ideal" consumption drop in the world of perfect insurance markets. Plugging this expression back into (19) yields

$$
\begin{aligned}
\gamma & =\widehat{\gamma}+\frac{c_{\text {unemp }}}{\widetilde{w}-b} \gamma \frac{\Delta c^{*}}{c} \\
& \Rightarrow \gamma=\widehat{\gamma} /\left(1-\frac{c_{\text {unemp }}}{\widetilde{w}-b} \frac{\Delta c^{*}}{c}\right)
\end{aligned}
$$

To calibrate this formula, recall that $c_{\text {unemp }}=0.9 w$ at the mean UI replacement rate based on Gruber's estimates, and $b=0.5 w$, so

$$
\gamma=\widehat{\gamma} /\left(1-1.8 \frac{\Delta c^{*}}{c}\right)
$$

Using $\widehat{\gamma} \approx 5$ from the estimates of risk aversion assuming additivity, the complementaritycorrected estimates of $\gamma$ for various values of $\frac{\Delta c^{*}}{c}$ are given in the following table:

$$
\begin{array}{llllll}
\frac{\Delta c^{*}}{c} & -20 \% & -10 \% & 0 & 10 \% & 20 \% \\
\gamma & 3.7 & 4.2 & 5 & 6.1 & 7.8
\end{array}
$$

Note that $\frac{\Delta c^{*}}{c}=\frac{c^{e}-c^{u}}{c^{e}}<0$ implies that agents choose to have higher consumption while unemployed in a world of perfect insurance. 


\section{B Estimation of $\gamma$ with crowdout of $s$ and $y$}

This appendix proves that the estimator for $\gamma$ in (12) gives a lower bound for the true value of $\gamma$ in the more general case where savings (or other sources of income, $y$ ) are endogenously crowded out by the variations in UI benefits. I begin again from the agent's first order condition for $l$ when unemployed given in (8) but now permit $\frac{\partial s}{\partial b_{0}} \neq 0$ and $\frac{\partial s}{\partial b} \neq 0$. The proof when other income is also endogenous $\left(\frac{\partial y}{\partial b_{0}} \neq 0\right.$ and $\frac{\partial y}{\partial b} \neq 0$ is analogous to that below, with $s$ replaced by $y$, exploiting the convexity of $\eta$ instead of the concavity of $u$.

Implicit differentiation of (8) with respect to $b$ and $b_{0}$ yields

$$
\begin{aligned}
\frac{\partial l}{\partial b_{0}} & =-\frac{\left(1+\frac{\partial s}{\partial b_{0}}\right)(\widetilde{w}-b) u_{c c}}{(\widetilde{w}-b)^{2} u_{c c}-\psi_{l l}} \\
\frac{\partial l}{\partial b} & =\frac{\left.u_{c}-\left(1-l+\frac{\partial s}{\partial b}\right)\right)(\widetilde{w}-b) u_{c c}}{(\widetilde{w}-b)^{2} u_{c c}-\psi_{l l}}
\end{aligned}
$$

Let $\widehat{\gamma}$ denote the estimator for risk aversion derived in the text under the assumption of no crowdout.

$$
\begin{aligned}
\widehat{\gamma} & =\frac{\partial l / \partial b_{0}}{\partial l^{c} / \partial b} \frac{c_{\text {unemp }}}{\widetilde{w}-b}=\frac{\partial l / \partial b_{0}}{\frac{\partial l}{\partial b}-(1-l) \frac{\partial l}{\partial b_{0}}} \frac{c_{\text {unemp }}}{\widetilde{w}-b} \\
& =\frac{\left(1+\frac{\partial s}{\partial b_{0}}\right) u_{c c} c_{\text {unemp }}}{u_{c}-\left(\frac{\partial s}{\partial b}-(1-l) \frac{\partial s}{\partial b_{0}}\right)(\widetilde{w}-b) u_{c c}}=K \gamma \\
\text { where } K & =\frac{\left(1+\frac{\partial s}{\partial b_{0}}\right) u_{c}}{u_{c}-\left(\frac{\partial s}{\partial b}-(1-l) \frac{\partial s}{\partial b_{0}}\right)(\widetilde{w}-b) u_{c c}}
\end{aligned}
$$

The remainder of the proof establishes $K<1$, which suffices to show that $\widehat{\gamma}$ is a lower bound for $\gamma$. To sign the savings responses, I begin with the first-order condition that determines $s$ :

$$
u_{c}(w-s)=\delta\left[(1-p) u_{c}(s+\widetilde{w})+p u_{c}\left(s+y+b_{0}+b(1-l)+\widetilde{w} l\right)\right]
$$

Differentiating this condition yields

$$
\begin{aligned}
\frac{\partial s}{\partial b_{0}} & =-\frac{1+(\widetilde{w}-b) \frac{\partial l}{\partial b_{0}}}{u_{c c}\left(c_{1}\right)+\delta E u_{c c}\left(c_{2}\right)} \delta p u_{c c}\left(c_{2}^{u}\right) \\
\frac{\partial s}{\partial b} & =-\frac{1-l+(\widetilde{w}-b) \frac{\partial l}{\partial b}}{u_{c c}\left(c_{1}\right)+\delta E u_{c c}\left(c_{2}\right)} \delta p u_{c c}\left(c_{2}^{u}\right)
\end{aligned}
$$


Plugging in the expression for $\frac{\partial l}{\partial b_{0}}$ in (20) into the equation for $\frac{\partial s}{\partial b_{0}}$ and solving gives

$$
\begin{aligned}
\frac{\partial s}{\partial b_{0}} & =\frac{Q_{1}+Q_{1} Q_{2}}{1-Q_{1} Q_{2}}<0 \\
\text { where } Q_{1} & =-\frac{\delta p u_{c c}\left(c_{2}^{u}\right)}{u_{c c}\left(c_{1}\right)+\delta E u_{c c}\left(c_{2}\right)}<0 \\
\text { and } Q_{2} & =\frac{(\widetilde{w}-b)^{2} u_{c c}}{(\widetilde{w}-b)^{2} u_{c c}-\psi_{l l}}>0
\end{aligned}
$$

To sign the savings derivatives in the denominator of $K$, observe that

$$
\begin{aligned}
\frac{\partial s}{\partial b}-(1-l) \frac{\partial s}{\partial b_{0}} & =-\frac{\delta p(\widetilde{w}-b) u_{c c}\left(c_{2}^{u}\right)}{u_{c c}\left(c_{1}\right)+\delta E u_{c c}\left(c_{2}\right)}\left(\frac{\partial l}{\partial b}-(1-l) \frac{\partial l}{\partial b_{0}}\right) \\
& =-\frac{\delta p(\widetilde{w}-b) u_{c c}\left(c_{2}^{u}\right)}{u_{c c}\left(c_{1}\right)+\delta E u_{c c}\left(c_{2}\right)} \frac{\partial l^{c}}{\partial b}
\end{aligned}
$$

With the definitions of $Q_{1}$ and $Q_{2}$ as above, plugging in for $\frac{\partial l^{c}}{\partial b}$ and solving gives

$$
\frac{\partial s}{\partial b}-(1-l) \frac{\partial s}{\partial b_{0}}=\frac{Q_{1} Q_{2} u_{c}}{(\widetilde{w}-b) u_{c c}\left(1+Q_{1} Q_{2}\right)}>0
$$

because $\delta p<1 \Rightarrow Q_{1} Q_{2}>-1$.

Putting together these results implies that the denominator of $K$ is greater than $u_{c}$ and the numerator of $K$ is less than $u_{c}$, which together imply $K<1$, completing the proof. 


\section{Measurement of unemployment durations}

The measurement of unemployment durations in the SIPP differs from that in the CPS because it requires tabulation of responses to questions about employment at the weekly level. This appendix describes the method used to compute durations, which follows Cullen and Gruber (2000).

The SIPP reports the employment status of every individual over 15 years old for every week that they are in the sample. Weekly employment status (ES) can take the following values:

1 .With a job this week

2 .With a job, absent without pay, no time on layoff this week

3 .With a job, absent without pay, spent time on layoff this week

4 .Looking for a job this week

5 .Without a job, not looking for a job, not on layoff

A job separation is defined as a change in ES from 1 or 2 to 3 , 4, or 5 . The duration of unemployment is computed by summing the number of consecutive weeks that ES $>=3$, starting at the date of job separation and stopping when the individual finds a job that lasts for at least one month (i.e. reports a string of four consecutive $\mathrm{ES}=1$ or $\mathrm{ES}=2$ ). Individuals are defined as being on temporary layoff if they report $\mathrm{ES}=3$ at any point in the spell. They are included as "searching" if they report ES $=4$ at any point during their spell.

This method of computing durations results in a slightly different mean duration than that found in the CPS data. The mean spell in the SIPP lasts for 20.95 weeks before ending or being censored, whereas the US Department of Labor reports a mean duration of approximately 15 weeks. The official figure is computed from the length of ongoing spells for the cross-section of unemployed individuals who report they are looking for work in the CPS. The official definition therefore excludes the spells of individuals who become discouraged and stop searching for work. Unfortunately, these individuals cannot be identified in the SIPP because of the lack of reliable information on search behavior. At a weekly frequency, reports of job search are frequently interspersed with reports that the individual is not looking for a job; moreover, individuals often find jobs after reporting that they were not looking for one. Therefore, the only feasible measure of the length of an unemployment spell is to count the weeks from job separation to either job finding or censoring. While this is a valid definition of "unemployment," it should be distinguished from the more familiar measure, especially when the empirical results of this paper are compared to those of other studies. 
FIGURE 1

Sample Unemployment Insurance Benefit Paths

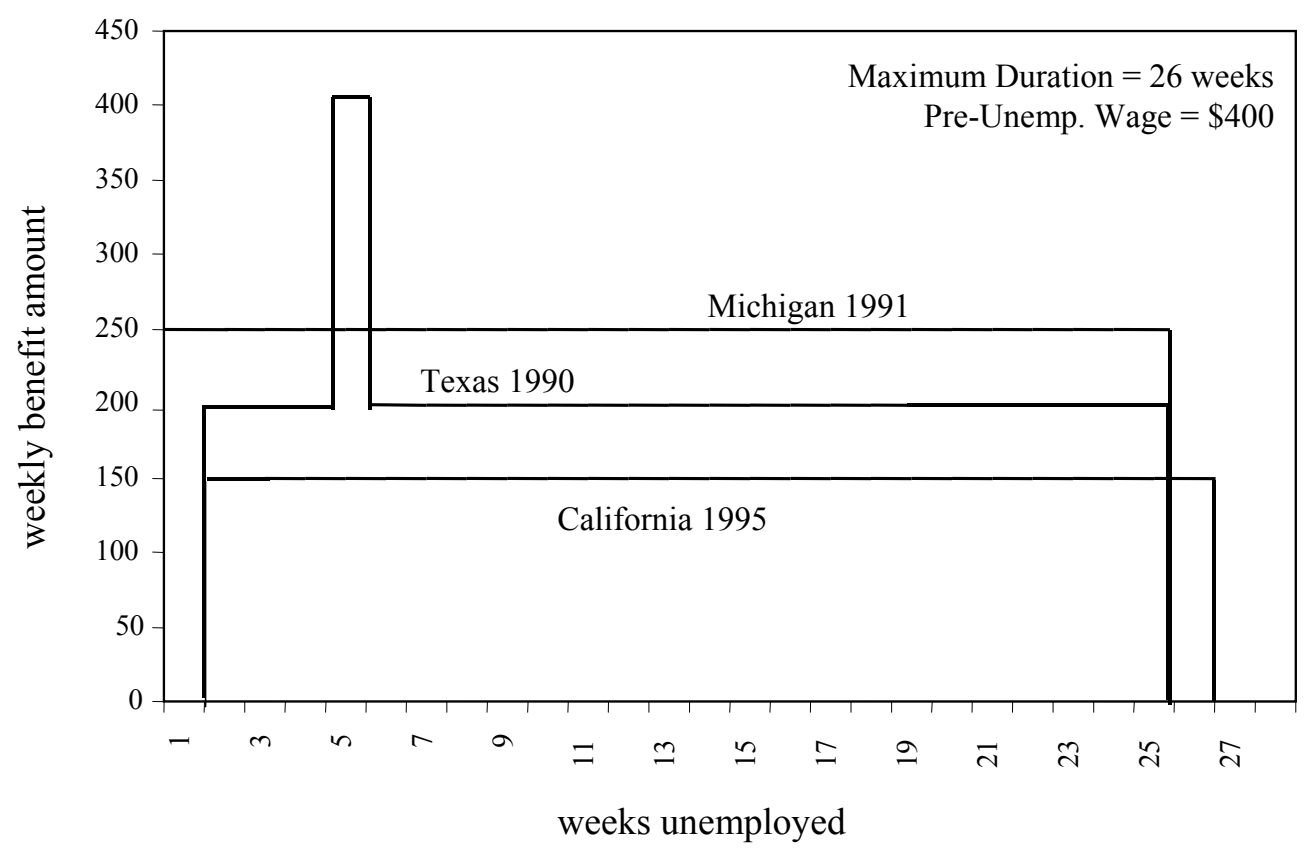

NOTE - Figure plots weekly unemployment insurance benefit payments in 1990 dollars for a claimant earning $\$ 400$ per week over the entire year prior to unemployment. MI has no waiting period; TX has a retroactive payment for the waiting period after 4 weeks of unemployment; and CA has a waiting period and no retroactive provision. Following the notation used in the paper, MI and TX are INC $=1$ states and $\mathrm{CA}$ is an INC $=0$ state. For this claimant, all three states have a maximum duration for UI benefits of 26 weeks; since CA has a one week waiting period, benefits terminate in the $27^{\text {th }}$ week after the job separation. 
FIGURE 2

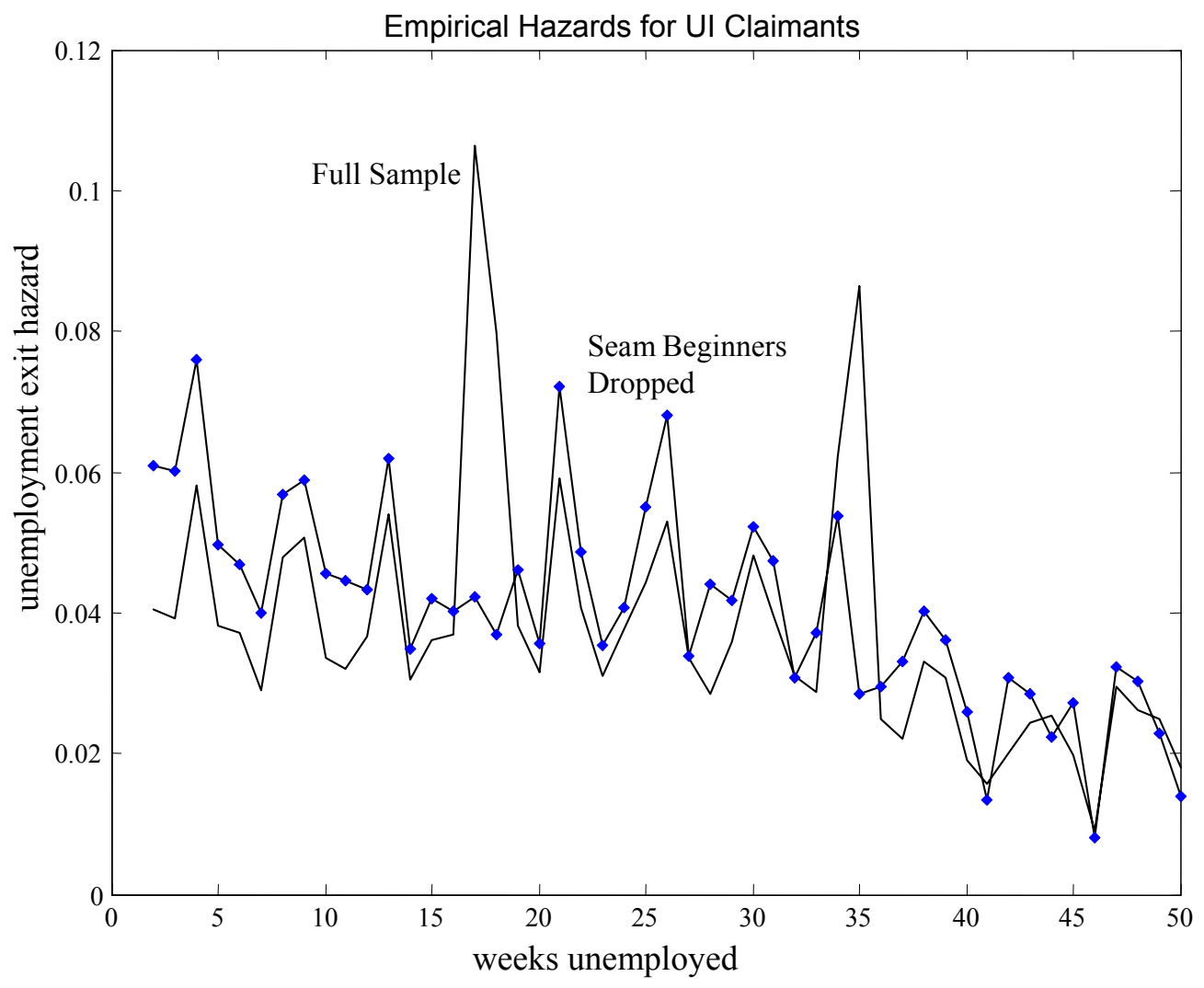

NOTE - Figure plots unemployment exit hazards for core sample. Data on unemployment durations is from the Survey of Income and Program Participation 1985-2000. The sample consists of all prime-aged males who (1) took up unemployment insurance benefits within one month of a job separation, (2) reported searching for a job at some point during the spell, (3) never reported that they were on temporary layoff, and (4) were unemployed for more than one week. The hazard rate in week $t$ is defined as the probability that an individual who is unemployed for $t$ or more weeks finds a job in week $t$. In the full sample, the spikes at $t=17$ and $t=35$ reflect a reporting artefact in the SIPP known as the seam effect; see text for details. 
FIGURE 3

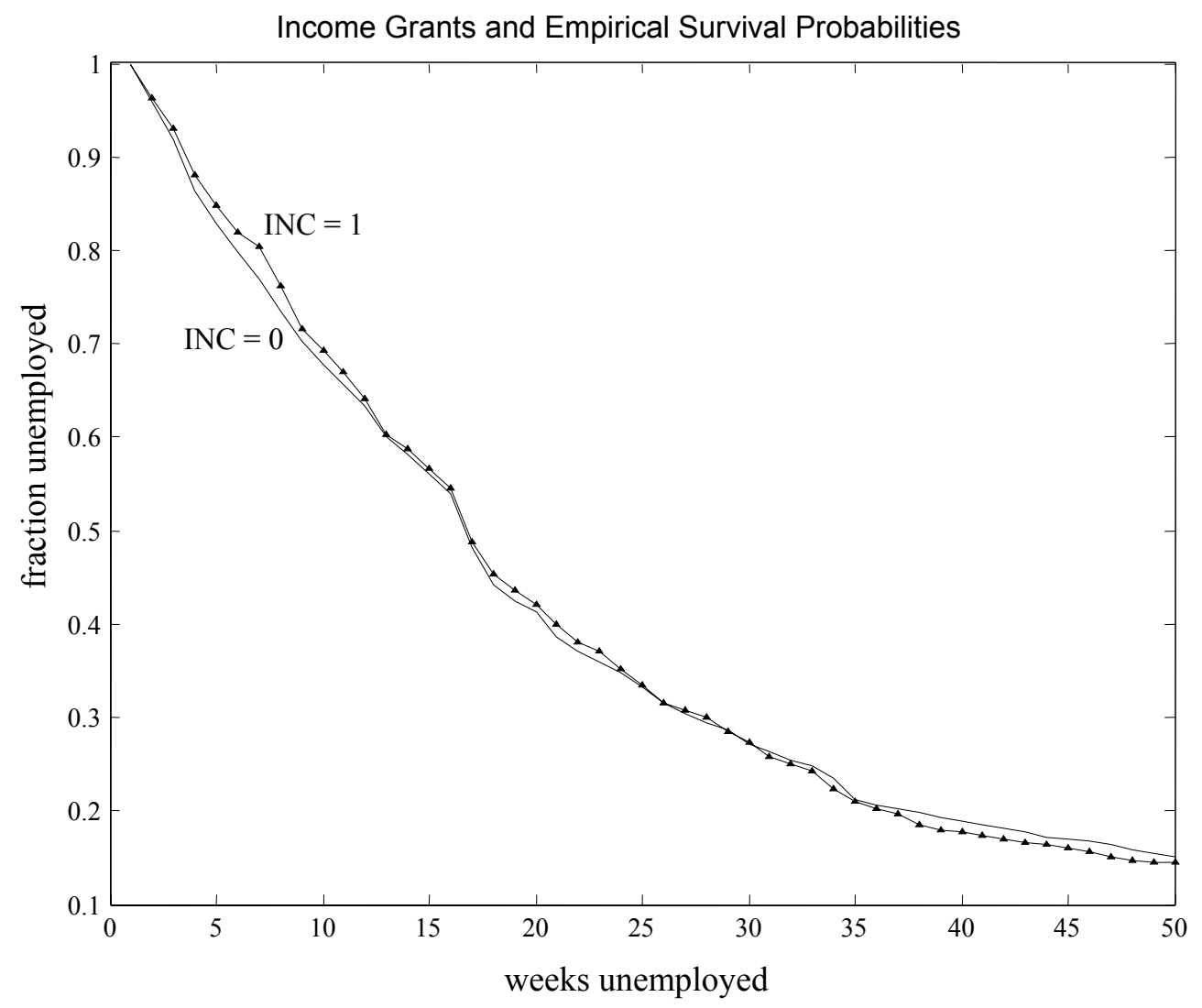

NOTE - Figure plots survival probabilities for two categories of unemployment insurance claimants: those who live in states that have a one-week waiting period for UI benefits and make no retroactive payment for this week $(\mathrm{INC}=0)$ and those who live in states that either have no waiting week or make a retroactive payment $(\mathrm{INC}=$ 1). Claimants in the INC $=1$ states effectively receive an extra week of UI benefits at the beginning of the spell relative to claimants in INC $=0$ states. See Figure 2 for description of sample selection procedures. 


\section{FIGURE 4}

UI Benefit Rates and Empirical Survival Probabilities

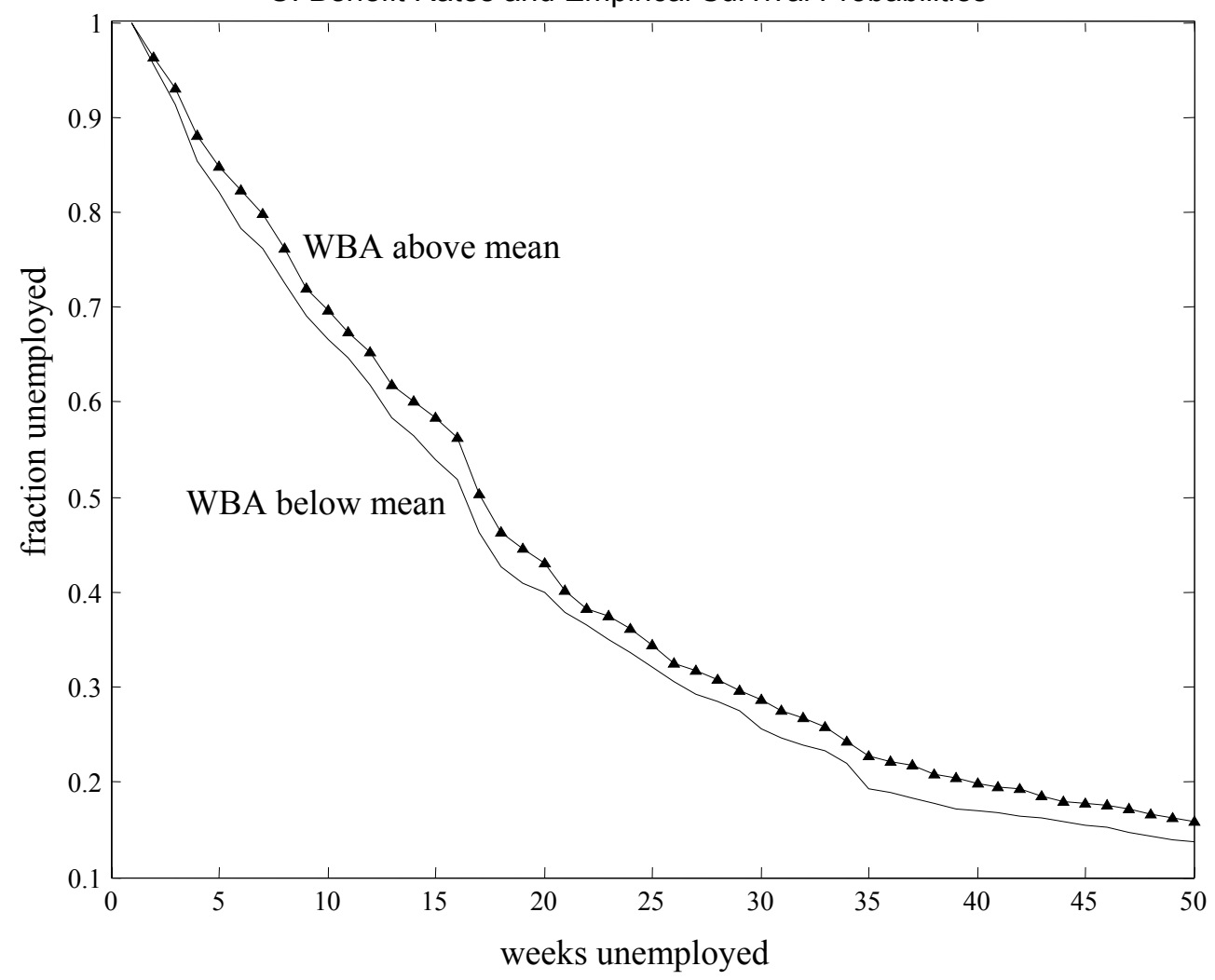

NOTE - Figure plots survival probabilities for two categories of unemployment insurance claimants: those who live in states with average weekly benefit amounts (WBA) below the sample mean and those who live in states with WBAs above the mean. See Figure 2 for description of sample selection procedures. 
FIGURE 5

UI Benefit Rate and Empirical Hazards

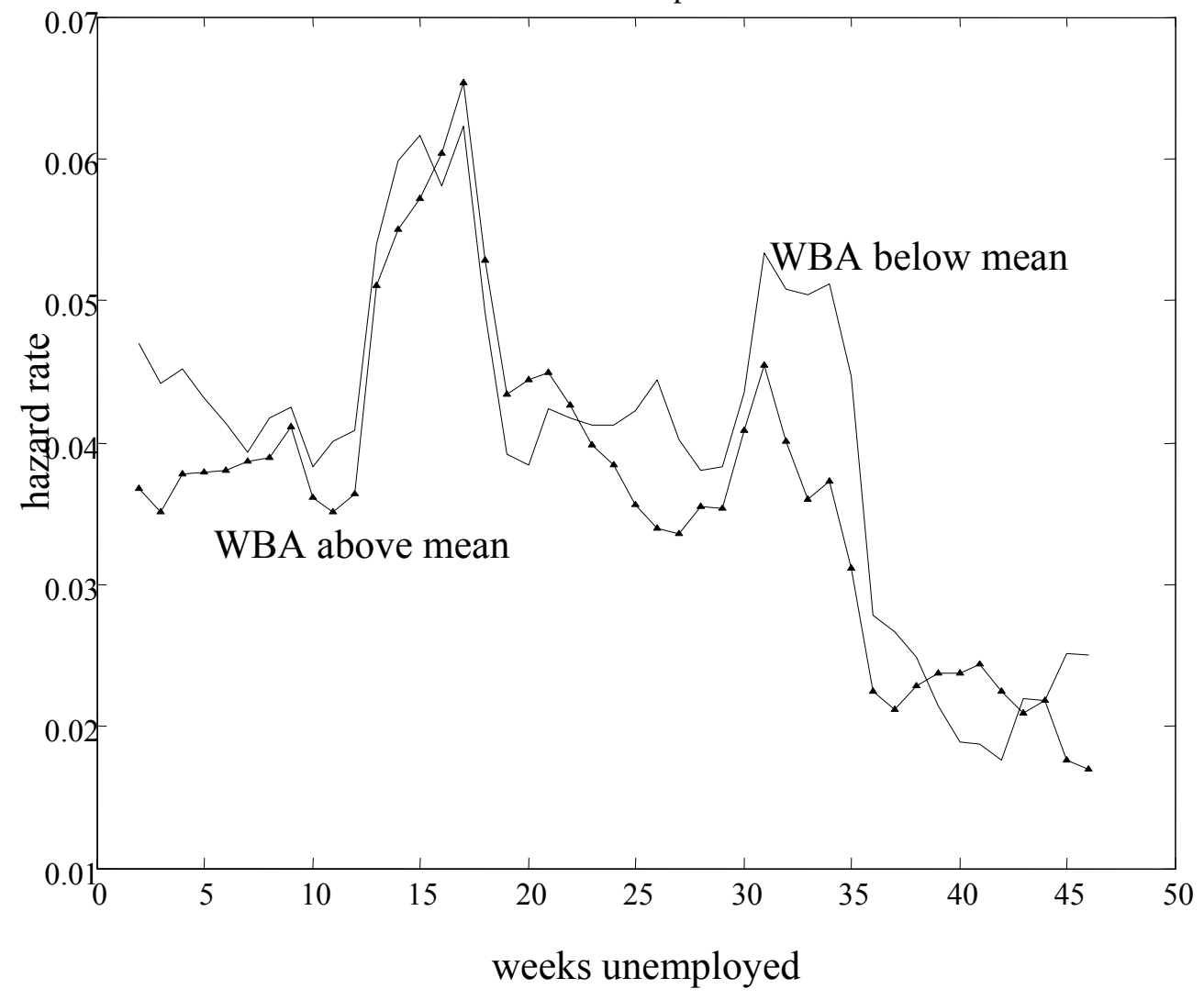

NOTE - Figure plots a five-week moving average of the empirical hazards for two categories of unemployment insurance claimants: those who live in states with average weekly benefit amounts (WBA) below the sample mean and those who live in states with WBAs above the mean. See Figure 2 for description of sample selection procedures. 
TABLE 1

DESCRIPTIVE STATISTICS FOR UI CLAIMANTS FROM THE SIPP

\begin{tabular}{lrrr}
\hline \hline & & & Standard \\
Variable & 37.00 & 35.00 & 11.08 \\
\hline Age & 0.61 & 1.00 & 0.49 \\
Married (yes = 1) & 12.07 & 12.00 & 3.06 \\
Education (years) & 0.52 & 0.00 & 0.96 \\
Dependents & 413.96 & 355.11 & 272.78 \\
Pre-unemployment weekly wage & $42,195.51$ & $35,344.00$ & $35,621.44$ \\
Annual pre-unemp family income & $32,053.37$ & $9,440.32$ & $49,494.13$ \\
Pre-unemp home equity & $22,715.79$ & $2,027.97$ & $64,997.21$ \\
Pre-unemp liquid wealth & $18,441.26$ & 186.32 & $66,588.72$ \\
Liquid wealth net of unsec. debt & 165.80 & 162.30 & 50.46 \\
Weekly Ul benefit amount & 0.86 & 1.00 & 0.35 \\
Waiting week (yes = 1) & 0.17 & 0.00 & 0.38 \\
Retroactive payment (yes = 1) & 32.11 & 26.00 & 6.42 \\
Maximum potential duration (weeks) & 6.60 & 6.50 & 1.70 \\
State unemployment rate & 20.89 & 16.00 & 21.03 \\
Weeks to job finding or censoring & 0.22 & 0.00 & 0.41 \\
Censored (yes = 1) & & &
\end{tabular}

NOTE - The values are based on tabulations from SIPP panels that span 1985-2000. The sample consists of the 4,457 prime-aged males who (1) took up unemployment insurance benefits within one month of a job separation, (2) reported searching for a job at some point during the spell, (3) never reported that they were on temporary layoff, and (4) were unemployed for more than one week. Wealth data are collected only in certain topical modules and are therefore available for only 2,530 observations. Liquid wealth is defined as total wealth minus home equity and vehicle equity. All monetary variables are in 1990 dollars. 
TABLE 2

SEMI-PARAMETRIC HAZARD MODEL ESTIMATES

\begin{tabular}{|c|c|c|c|c|c|}
\hline & $\begin{array}{ll}(1) \\
\end{array}$ & $\begin{array}{c}(2) \\
\text { With }\end{array}$ & $\begin{array}{c}(3) \\
\text { Simulated }\end{array}$ & $\begin{array}{c}(4) \\
\text { State } \\
\text { Fixed Effects }\end{array}$ & Non-UI \\
\hline Variable & Base Case & Controls & Benefits & Fixed Effects & Non-UI \\
\hline Log State Avg. UI Weekly Benefit Amt & $\begin{array}{c}0.655 \\
(0.151)\end{array}$ & $\begin{array}{c}0.630 \\
(0.118)\end{array}$ & & $\begin{array}{c}0.595 \\
(0.178)\end{array}$ & $\begin{array}{c}0.974 \\
(0.097)\end{array}$ \\
\hline Wks Unemp * Log Avg. WBA & $\begin{array}{c}1.006 \\
(0.008)\end{array}$ & $\begin{array}{c}1.004 \\
(0.008)\end{array}$ & & $\begin{array}{c}1.002 \\
(0.009)\end{array}$ & $\begin{array}{c}1.003 \\
(0.005)\end{array}$ \\
\hline$\left(\right.$ Wks Unemp>MaxDur) ${ }^{*}$ Log Avg WBA & $\begin{array}{c}1.031 \\
(0.020)\end{array}$ & $\begin{array}{c}1.023 \\
(0.020)\end{array}$ & & $\begin{array}{c}1.021 \\
(0.021)\end{array}$ & $\begin{array}{c}0.985 \\
(0.011)\end{array}$ \\
\hline Time-Varying Income Effects: & & & & & \\
\hline INC 1 & $\begin{array}{c}0.886 \\
(0.073)\end{array}$ & $\begin{array}{c}0.882 \\
(0.076)\end{array}$ & $\begin{array}{c}0.876 \\
(0.081)\end{array}$ & $\begin{array}{c}0.895 \\
(0.142)\end{array}$ & $\begin{array}{c}1.046 \\
(0.046)\end{array}$ \\
\hline INC 2 & $\begin{array}{c}0.921 \\
(0.103)\end{array}$ & $\begin{array}{c}0.908 \\
(0.084)\end{array}$ & $\begin{array}{c}0.904 \\
(0.085)\end{array}$ & $\begin{array}{c}0.926 \\
(0.126)\end{array}$ & $\begin{array}{c}0.984 \\
(0.042)\end{array}$ \\
\hline INC 3 & $\begin{array}{c}1.144 \\
(0.145)\end{array}$ & $\begin{array}{c}1.110 \\
(0.128)\end{array}$ & $\begin{array}{c}1.110 \\
(0.124)\end{array}$ & $\begin{array}{c}1.130 \\
(0.165)\end{array}$ & $\begin{array}{c}1.058 \\
(0.071)\end{array}$ \\
\hline INC 4 & $\begin{array}{c}1.010 \\
(0.115)\end{array}$ & $\begin{array}{c}1.006 \\
(0.099)\end{array}$ & $\begin{array}{c}1.017 \\
(0.100)\end{array}$ & $\begin{array}{c}1.022 \\
(0.122)\end{array}$ & $\begin{array}{c}1.030 \\
(0.061)\end{array}$ \\
\hline INC 5-12 & $\begin{array}{c}1.030 \\
(0.065)\end{array}$ & $\begin{array}{c}1.027 \\
(0.058)\end{array}$ & $\begin{array}{c}1.068 \\
(0.067)\end{array}$ & $\begin{array}{c}1.060 \\
(0.124)\end{array}$ & $\begin{array}{c}1.095 \\
(0.045)\end{array}$ \\
\hline State unemployment rate & $\begin{array}{c}0.960 \\
(0.011)\end{array}$ & $\begin{array}{c}0.951 \\
(0.013)\end{array}$ & $\begin{array}{c}0.956 \\
(0.015)\end{array}$ & $\begin{array}{c}0.995 \\
(0.016)\end{array}$ & $\begin{array}{c}0.976 \\
(0.008)\end{array}$ \\
\hline $1=$ on seam & $\begin{array}{c}6.747 \\
(0.260)\end{array}$ & $\begin{array}{c}6.256 \\
(0.213)\end{array}$ & $\begin{array}{c}6.236 \\
(0.212)\end{array}$ & $\begin{array}{c}6.248 \\
(0.214)\end{array}$ & $\begin{array}{c}6.422 \\
(0.201)\end{array}$ \\
\hline Age & & $\begin{array}{c}0.983 \\
(0.002)\end{array}$ & $\begin{array}{c}0.986 \\
(0.002)\end{array}$ & $\begin{array}{c}0.982 \\
(0.002)\end{array}$ & $\begin{array}{c}0.987 \\
(0.001)\end{array}$ \\
\hline $1=$ married & & $\begin{array}{c}1.185 \\
(0.048)\end{array}$ & $\begin{array}{c}1.205 \\
(0.047)\end{array}$ & $\begin{array}{c}1.195 \\
(0.049)\end{array}$ & $\begin{array}{c}1.317 \\
(0.034)\end{array}$ \\
\hline Years of schooling & & $\begin{array}{c}1.013 \\
(0.007)\end{array}$ & $\begin{array}{c}1.022 \\
(0.008)\end{array}$ & $\begin{array}{c}1.011 \\
(0.007)\end{array}$ & $\begin{array}{c}1.030 \\
(0.005)\end{array}$ \\
\hline 1 = working spouse & & $\begin{array}{c}1.063 \\
(0.048)\end{array}$ & $\begin{array}{c}1.060 \\
(0.047)\end{array}$ & $\begin{array}{c}1.057 \\
(0.048)\end{array}$ & $\begin{array}{c}0.930 \\
(0.028)\end{array}$ \\
\hline Log Simulated UI WBA & & & $\begin{array}{c}0.696 \\
(0.113)\end{array}$ & & \\
\hline Wks Unemp * Log Sim WBA & & & $\begin{array}{c}0.988 \\
(0.006)\end{array}$ & & \\
\hline (Wks Unemp>MaxDur) * Log Sim WBA & & & $\begin{array}{c}1.027 \\
(0.020)\end{array}$ & & \\
\hline Sample Size & 4457 & 4430 & 4430 & 4430 & 13108 \\
\hline
\end{tabular}

NOTE - The sample for columns 1-4 consists of unemployed men from the SIPP who satisfy the restrictions described in Table 1. The sample for column 5 consists of unemployed men who did not report receipt of UI benefits at any point. Each column reports estimates of hazard ratios for a Cox model. Standard errors, reported in parentheses, are clustered by state. Notation for the time-varying income effect is as follows: INC $=1$ in states where individuals receive an additional week of benefits at beginning of spell. The INC 1 variable captures the effect of the INC dummy in month 1, INC 2 in month 2, etc. The on-seam variable indicates whether an individual is on a seam between SIPP interviews. Columns 1,2, 4, and 5 use average weekly benefits in a (state, year) pair in place of the individual UI benefit rate. Column 3 uses simulated individual benefits based on the procedure described in the text. Columns 2-5 include industry, occupation, year, and month dummies, and a 10-piece log-linear wage spline. Column 4 also includes state dummies. 
TABLE 3

ADDITIONAL HAZARD MODEL ESTIMATES

\begin{tabular}{|c|c|c|c|c|c|}
\hline Variable & $\begin{array}{c}\text { (6) } \\
\text { Retro } \\
\text { Excluded }\end{array}$ & $\begin{array}{c}(7) \\
\text { Waiting Per } \\
\text { Excluded } \\
\end{array}$ & $\begin{array}{c}(8) \\
\text { Temp } \\
\text { Layoffs }\end{array}$ & $\begin{array}{c}\text { (9) } \\
\text { All UI } \\
\text { Recipients } \\
\end{array}$ & $\begin{array}{c}(10) \\
\text { Maximum } \\
\text { Benefits } \\
\end{array}$ \\
\hline \multirow[t]{2}{*}{ Log UI Benefit Level } & 0.659 & 0.608 & 0.650 & 0.743 & \\
\hline & $(0.131)$ & $(0.127)$ & $(0.125)$ & $(0.133)$ & \\
\hline \multirow[t]{2}{*}{ Wks Unemp * Log UI Benefit Level } & 1.004 & 1.005 & 1.003 & 1.002 & \\
\hline & $(0.009)$ & $(0.010)$ & $(0.008)$ & $(0.007)$ & \\
\hline \multirow[t]{2}{*}{$($ Wks Unemp $>$ MaxDur) * Log UI Ben } & 1.013 & 1.012 & 1.021 & 1.016 & \\
\hline & $(0.023)$ & $(0.022)$ & $(0.019)$ & $(0.010)$ & \\
\hline \multicolumn{6}{|l|}{ Time-Varying Income Effects } \\
\hline INC 1 & $\begin{array}{c}0.893 \\
(0.120)\end{array}$ & $\begin{array}{c}0.862 \\
(0.080)\end{array}$ & $\begin{array}{c}0.877 \\
(0.073)\end{array}$ & $\begin{array}{c}0.902 \\
(0.075)\end{array}$ & $\begin{array}{c}0.700 \\
(0.124)\end{array}$ \\
\hline INC 2 & $\begin{array}{c}0.941 \\
(0.123)\end{array}$ & $\begin{array}{c}0.875 \\
(0.084)\end{array}$ & $\begin{array}{c}0.898 \\
(0.081)\end{array}$ & $\begin{array}{c}1.008 \\
(0.072)\end{array}$ & $\begin{array}{c}1.134 \\
(0.148)\end{array}$ \\
\hline INC 3 & $\begin{array}{c}1.168 \\
(0.150)\end{array}$ & $\begin{array}{c}1.057 \\
(0.160)\end{array}$ & $\begin{array}{c}1.123 \\
(0.118)\end{array}$ & $\begin{array}{l}1.128 \\
(0.103)\end{array}$ & $\begin{array}{c}1.387 \\
(0.252)\end{array}$ \\
\hline INC 4 & $\begin{array}{c}0.930 \\
(0.147)\end{array}$ & $\begin{array}{c}1.056 \\
(0.110)\end{array}$ & $\begin{array}{c}1.040 \\
(0.099)\end{array}$ & $\begin{array}{c}1.091 \\
(0.097)\end{array}$ & $\begin{array}{c}1.066 \\
(0.119)\end{array}$ \\
\hline INC 5-12 & $\begin{array}{c}0.993 \\
(0.065)\end{array}$ & $\begin{array}{c}1.038 \\
(0.062)\end{array}$ & $\begin{array}{c}1.022 \\
(0.056)\end{array}$ & $\begin{array}{c}1.083 \\
(0.061)\end{array}$ & $\begin{array}{c}1.119 \\
(0.081)\end{array}$ \\
\hline State unemployment rate & $\begin{array}{c}0.952 \\
(0.013)\end{array}$ & $\begin{array}{c}0.948 \\
(0.014)\end{array}$ & $\begin{array}{c}0.956 \\
(0.013)\end{array}$ & $\begin{array}{c}0.961 \\
(0.010)\end{array}$ & $\begin{array}{c}0.956 \\
(0.016)\end{array}$ \\
\hline 1 = on seam & $\begin{array}{c}6.164 \\
(0.234)\end{array}$ & $\begin{array}{c}6.232 \\
(0.237)\end{array}$ & $\begin{array}{c}5.940 \\
(0.197)\end{array}$ & $\begin{array}{c}5.951 \\
(0.203)\end{array}$ & $\begin{array}{c}6.106 \\
(0.286)\end{array}$ \\
\hline Age & $\begin{array}{c}0.982 \\
(0.002)\end{array}$ & $\begin{array}{c}0.983 \\
(0.002)\end{array}$ & $\begin{array}{c}0.983 \\
(0.002)\end{array}$ & $\begin{array}{c}0.983 \\
(0.002)\end{array}$ & $\begin{array}{c}0.981 \\
(0.003)\end{array}$ \\
\hline $1=$ married & $\begin{array}{c}1.183 \\
(0.054)\end{array}$ & $\begin{array}{c}1.156 \\
(0.052)\end{array}$ & $\begin{array}{c}1.187 \\
(0.048)\end{array}$ & $\begin{array}{c}1.250 \\
(0.040)\end{array}$ & $\begin{array}{c}1.243 \\
(0.077)\end{array}$ \\
\hline Years of schooling & $\begin{array}{c}1.011 \\
(0.008)\end{array}$ & $\begin{array}{c}1.009 \\
(0.007)\end{array}$ & $\begin{array}{c}1.013 \\
(0.008)\end{array}$ & $\begin{array}{c}1.015 \\
(0.005)\end{array}$ & $\begin{array}{c}1.004 \\
(0.009)\end{array}$ \\
\hline 1 = working spouse & $\begin{array}{c}1.077 \\
(0.051)\end{array}$ & $\begin{array}{c}1.112 \\
(0.053)\end{array}$ & $\begin{array}{c}1.063 \\
(0.045)\end{array}$ & $\begin{array}{c}1.026 \\
(0.034)\end{array}$ & $\begin{array}{c}1.031 \\
(0.052)\end{array}$ \\
\hline Log State Max UI WBA & & & & & $\begin{array}{c}0.877 \\
(0.171)\end{array}$ \\
\hline Wks Unemp * Log Max WBA & & & & & $\begin{array}{c}0.989 \\
(0.011)\end{array}$ \\
\hline (Wks Unemp>MaxDur) ${ }^{*}$ Log Max WBA & & & & & $\begin{array}{c}1.027 \\
(0.035)\end{array}$ \\
\hline Sample Size & 3687 & 3837 & 4682 & 6866 & 1715 \\
\hline
\end{tabular}

NOTE - Each column reports estimates of hazard ratios for a Cox model with a different sample. Column 6 excludes states that make retroactive payments for their waiting weeks. Column 7 excludes states that do not have a waiting week. Column 8 adds individuals on temporary layoff to the core sample described in Table 1. Column 9 adds UI recipients who did not take up UI in the first month to the core sample. Column 10 includes only those in the core sample who report a weekly wage above $\$ 400$. All columns include industry, occupation, year, and month dummies, and a 10-piece log-linear wage spline. Columns 6-9 use average weekly benefits in a (state, year) pair in place of the individual UI benefit rate. Column 10 uses the maximum weekly benefit amount in a given (state, year). Standard errors, reported in parentheses, are clustered by state. See Table 2 for descriptions of the INC and on-seam variables. 